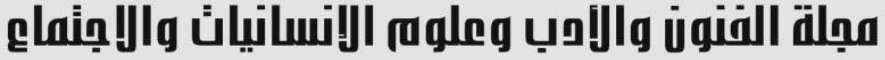

Journal of Arts, Literature, Humanities and Social Sciences

\section{الارتداد الماضوي في قصيدة النثر العراقية (دراسةُ ثُقافية)}

\section{المدرس الاكتور : أماني حارث مالك الغانمي

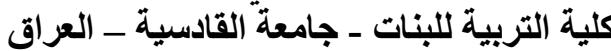 amani.harith12@gmail.com : الايميل}

قصيدة النثر هي ذللك الثكل الفني الذي يسعى الى التخلص من قيود الثعر العربي والتحرر من الالتزام بالقو اعد الموروثة فضلاً عن كونها نصاً مفتوحاً على فنون مجاورة ، وقد استطاعت قصيدة النثر أن تخرق تاريخاً أمتد لقرون بـن عديدة من الذائقة الجمالية وتسيدت المشهد الشعري العربي ، فهذه السيادة نقف منها بمسافة لطرح تساؤلات عديدة منها ، هل قصيدة النثر حالة شعرية خاصة و انها ليست امتداد للشعرية العربية بشكليها (العمودي و التفعيلي)؟ وهل ينطبق على شعر اء قصيدة النثر مقولة أودنيس ان شاعر النثر متمرد ورافض بل هو خالق وسيد ولا يقبل بقو اعد السلف لأنه ليس تلميذاً كثاعر العمود؟ وهل استطاع شاعر النثر ان يبتكر لغة وتقنية خاصة به يقدم من خلالها رؤية جديدة للعالم مو اكبة للحداثة وتمتلك طاقة الخلق الفني بعد أن اتخذ من النتر شكلاً لكتابة القصيدة ؟ اما المنهج الذي اتخذته الباحثة هو المنهج الثقافي الذي يدرس ظاهرة ثقافية ويهنم باستكثاف الأنساق الثقافية

المضمرة ويدرسها في سياقها المرجعي بتنو عاته المختلفة فهماً وتفسيراً.

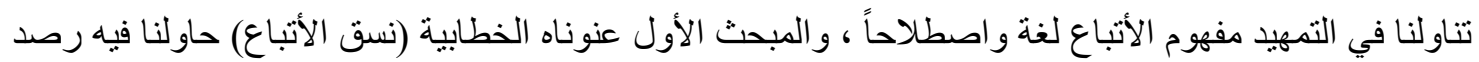
محاولات الحداثة في النصوص قيد الدراسة ، أما المبحث الثاني عنوناه بنسق الفحولة تحدثنا فيه عن الفحولة في القصيدة النسوية ثم الخاتمة وفيها ابرز النتائج التي توصل اليها البحث. الكلمات المفتاحية: الارتداد، الماضوي، قصيدة النثر ، النثر في العراق. 


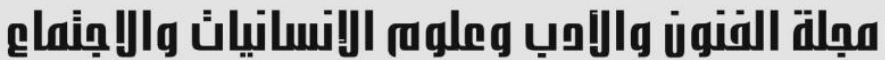

Journal of Arts, Literature, Humanities and Social Sciences

\section{Recoil in the Past in the Iraqi Prose Poem (Cultural study)}

\author{
Ph.D. Amani Harith Malik Al-Ghanmi \\ College of Education for Girls - Al-Qadisiyah University - Iraq \\ Email: amani.harith12@gmail.com
}

\begin{abstract}
Prose poem is that form of art that seeks to get rid of the restrictions of Arab poetry and freedom from adherence to the rules inherited, as well as being an open text on nearby art, the prose poem was able to break a history that extended for many centuries of aesthetic taste and dominated the Arab poetry scene, this sovereignty we stand by a distance to ask several questions, of which, is the prose poem a special poetic condition and it is not an extension of the Arab poetry in its form (vertical and emotional) ? does it apply to the poets of the prose poem, saying that the poet of prose is rebellious and rejected, but is a creator and master does not accept the rules of the predecessor, because he is not a pupil with a columnist? Can a prose poet invert a language and technique of his own through which to provide a new vision for the world to keep abreast of modernity and possess the energy of artistic creation after taking the prose form to write the poem? The approach adopted by the research is the cultural approach, which examines a cultural phenomenon and is interested in exploring the cultural patterns covered and taught in the context of reference cultural diversity.

In the preface we discussed the concept of following language and terminology the first article dealt with the pattern of follow-up attempts to monitor the attempts of modernity in the texts under study, as for the second section of the topic, we talked about the obsession in the feminist poem and then the conclusion in which the most prominent results reached by the researcher.
\end{abstract}

Keywords: apostasy, past, prose poem, prose in Iraq. 


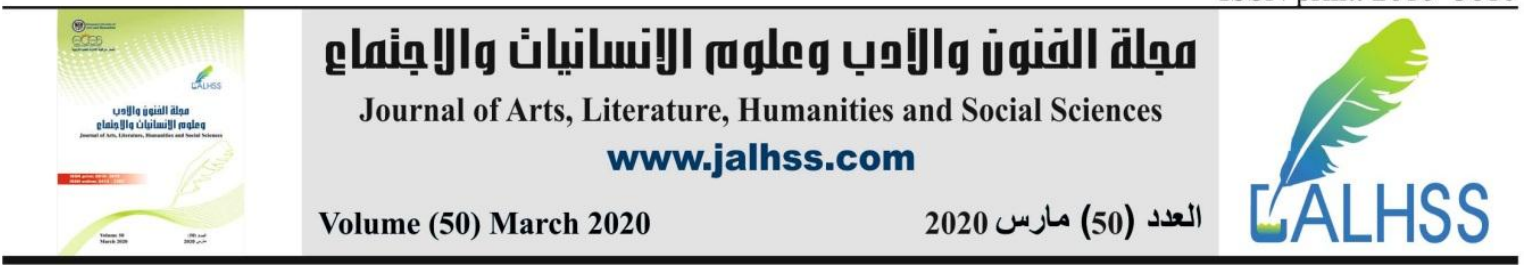

\section{التمهيد (مفهوم الأتباع)}

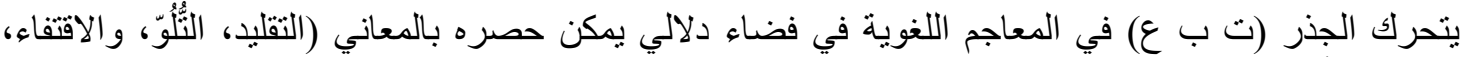

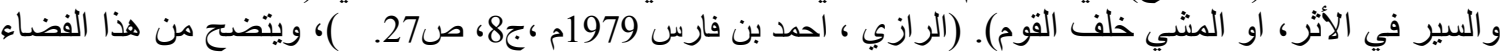

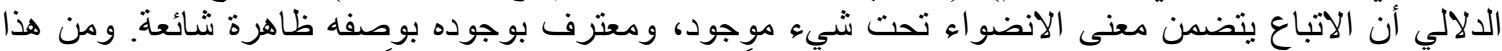

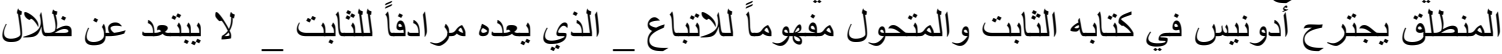

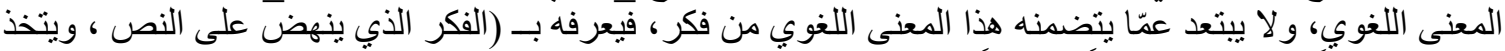

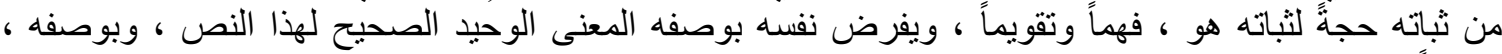

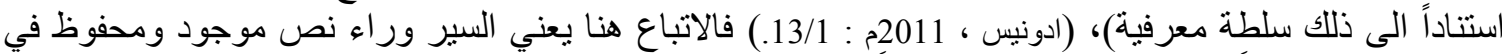
الذاكرة الثقافية سيراً يجعل النص الموجةد سلفاً يُجيب عن اسئلة الر الهن ، ويملك صورة شاملة ومفصلة لخارطة

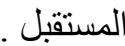

و الثاعر الذي تتحرك طاقته الشعرية في فضاء الفكر الاتباعي ، ويرسم عو المه بوعي الثابت الفكري القار

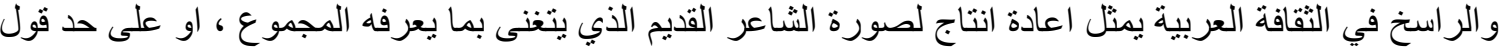

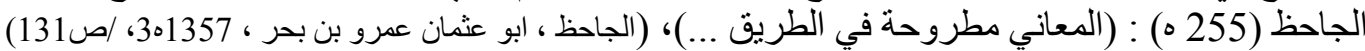

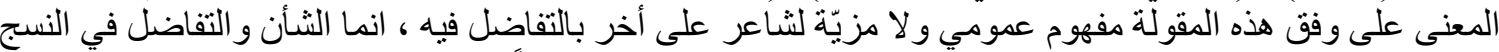

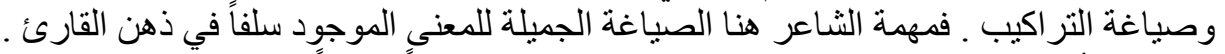

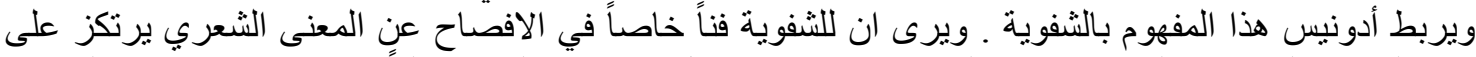

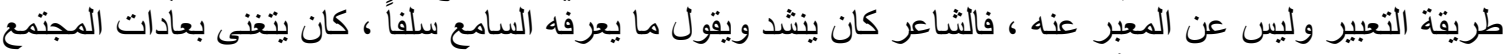

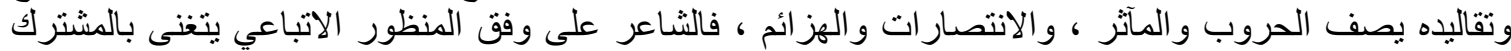

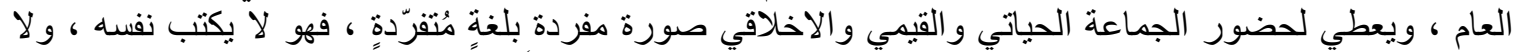

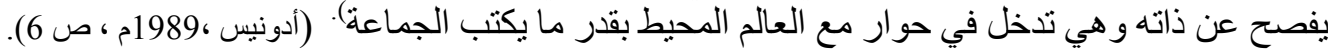

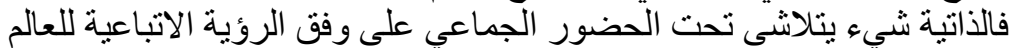

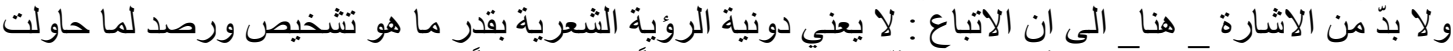

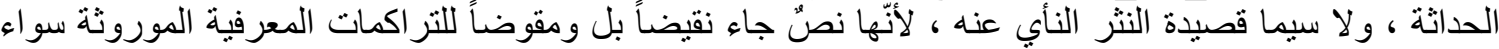

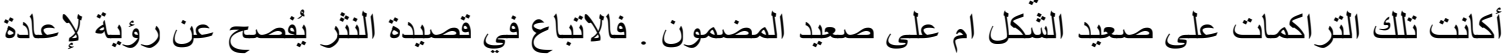

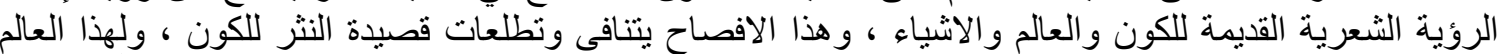

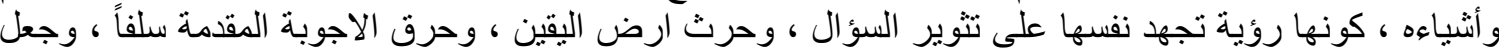

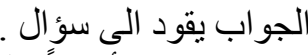

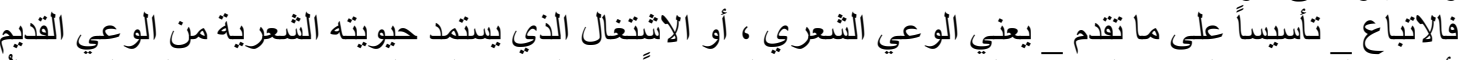

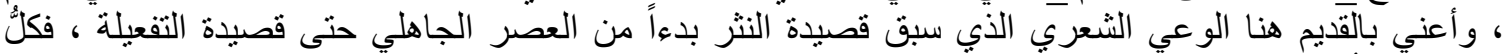

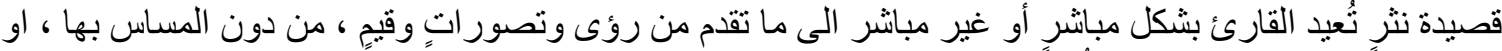

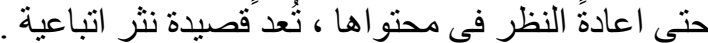

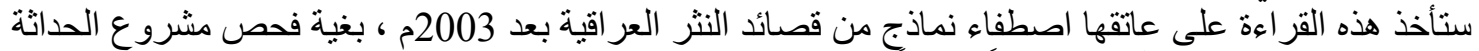

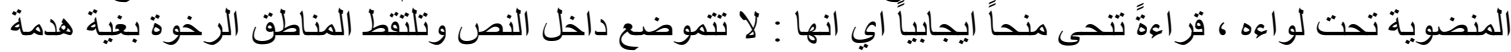

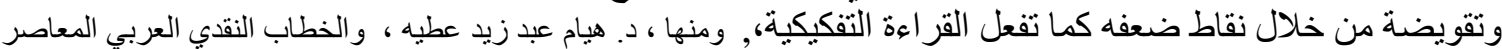

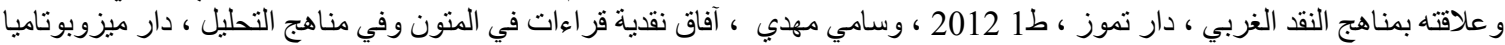

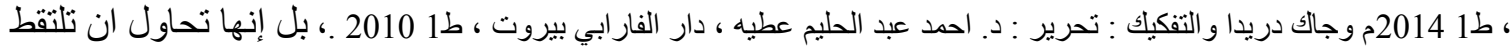

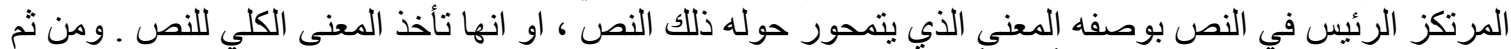

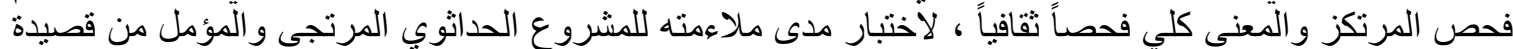
النتر ان تنشئه عربياً.

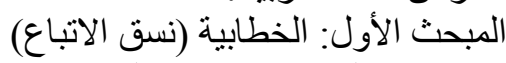

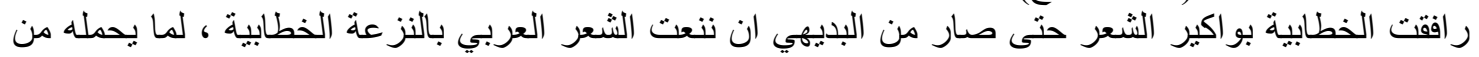

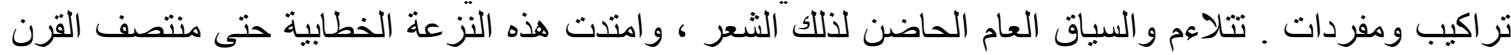




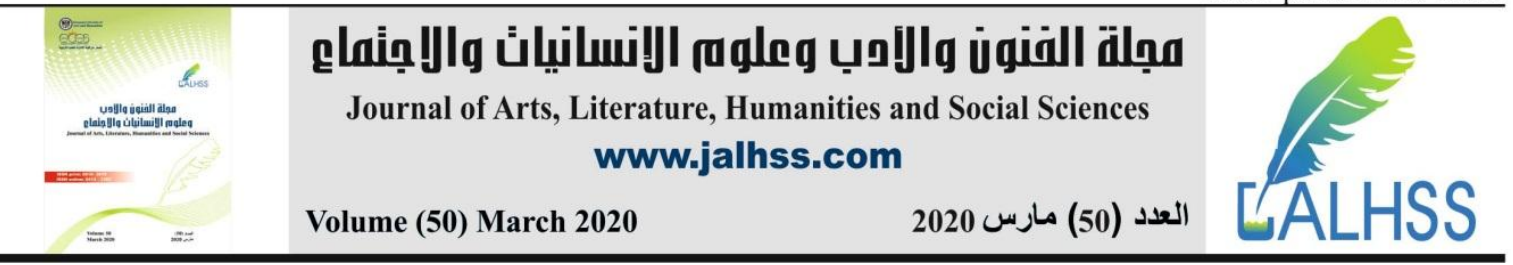

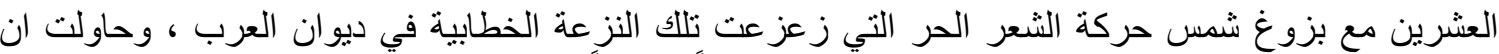

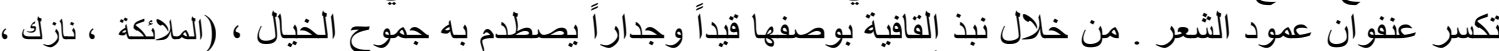

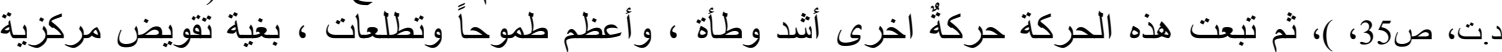

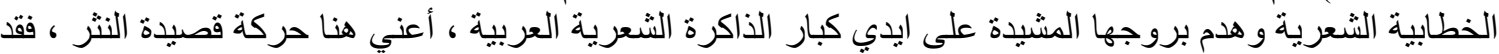

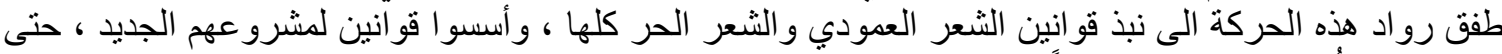

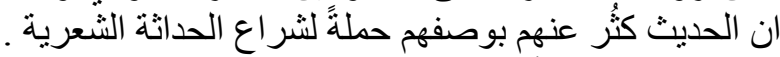
هذه القراءة ستأخذ على عاتقها اصطفاء نماذج من قصيدة النثر ومحاولة تفكيكها بغية الوقوف على على المشروع

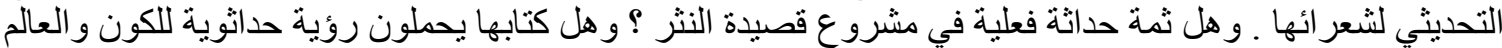

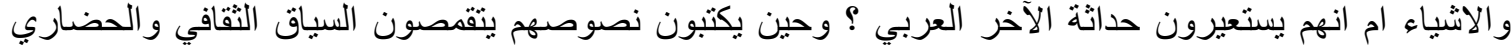

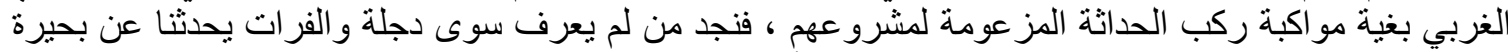
البجع ، ومن لم يشاهد سوى الحيوانات المنتشرة في الأزقة العر اقية ، يتحدث عن الدب القئ القطبي وهو يداعب كريات الثلج . الثع ،

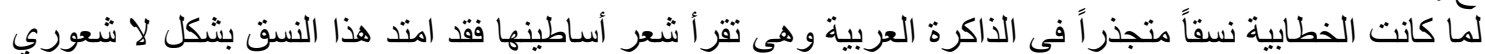

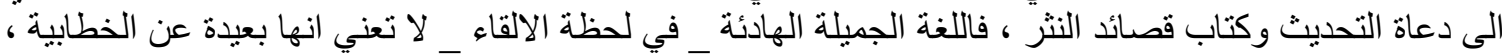

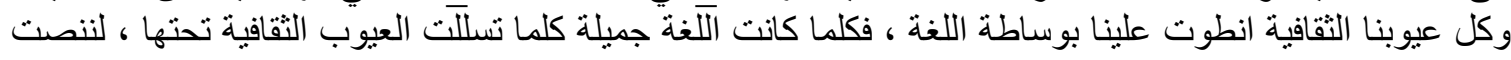

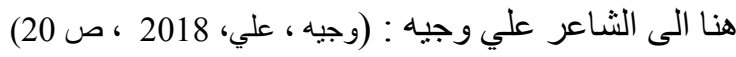

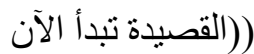

$$
\begin{aligned}
& \text { أقول } \\
& \text { وماذا في الأمر ؟ } \\
& \text { أحبّلك هكذا في الأر }
\end{aligned}
$$

بلا لون اضافي على عينيك الساخنتين

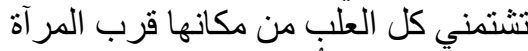

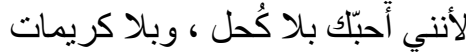
ولا أحمر شفاه (........))

انتماء هذه القصيدة لجنس قصيدة النثر يجعلنا نترقب منها : كسر السائد ، الصدمة في التلقي ، الجدة ، الخيال التيال

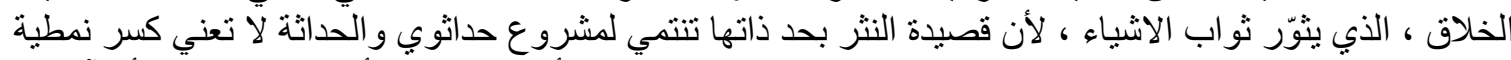

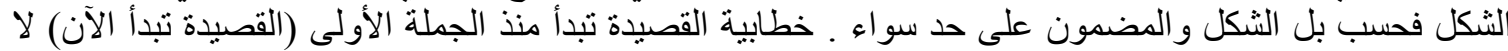

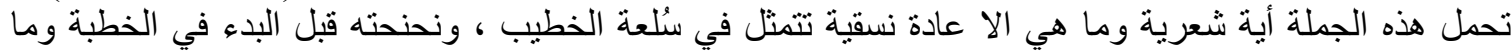

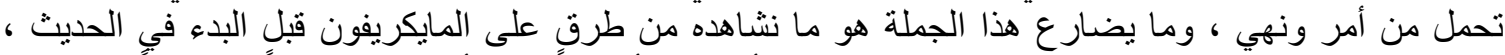

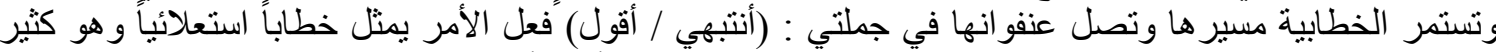

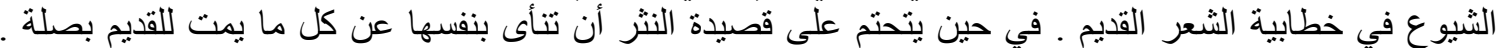

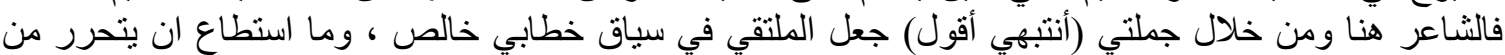

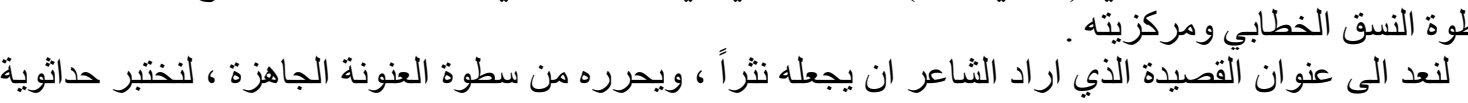

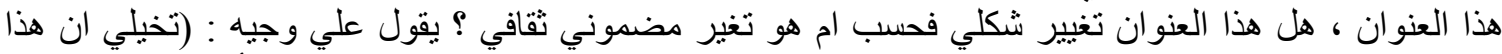

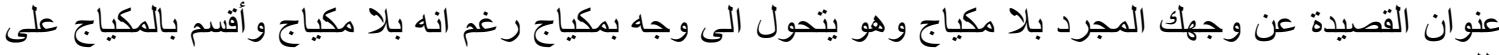

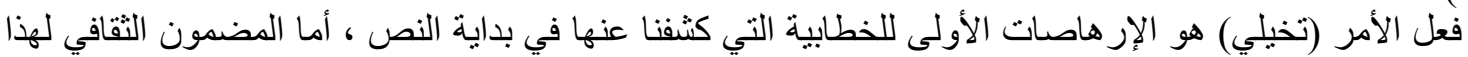
العنوان فهو انعكاس لسلطة التعالي والقطيعة الأزلية بعبارة أخرى أن الثاعر هنا نعالى على المرأة التي يأمرها 


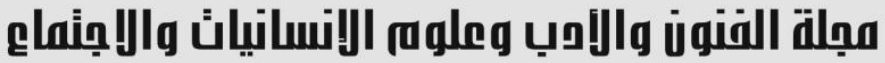

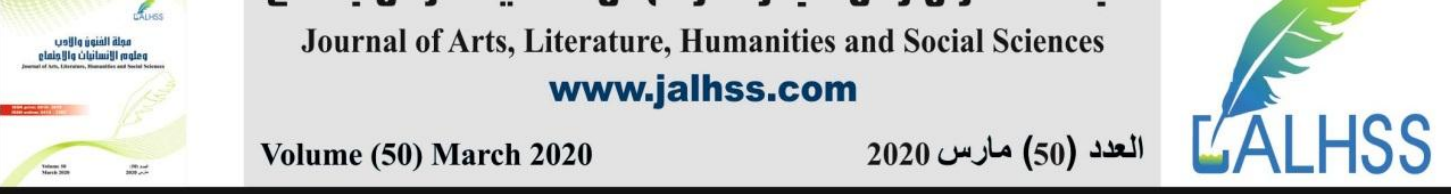

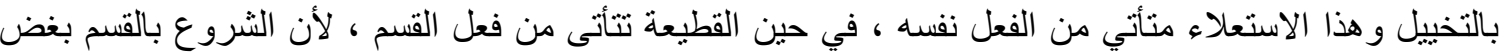

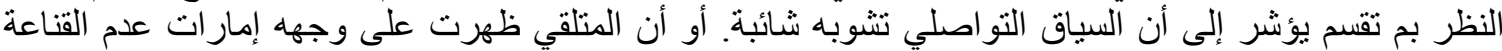

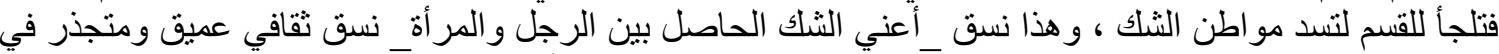

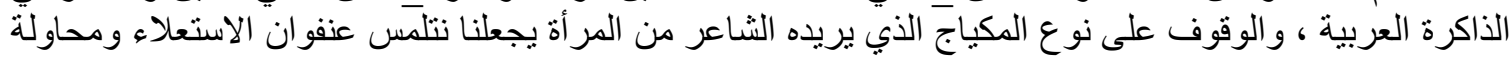

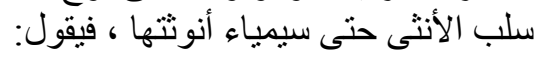

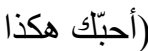

بلا لون إضافي على عينيك الساخنتين

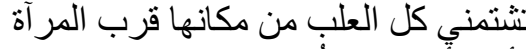

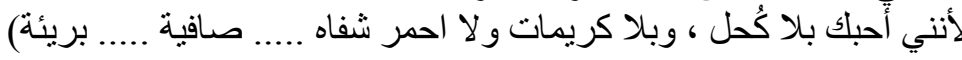

هذا الحب الذي يجرد المرأة من سيمباء الأنوثة العصرية ، تحت ذريعة أنه يحبها صافية وبريئة وهذان الصفتان

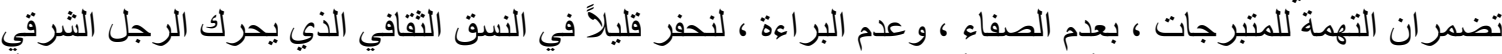

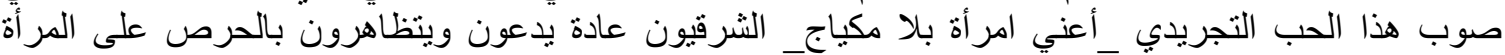

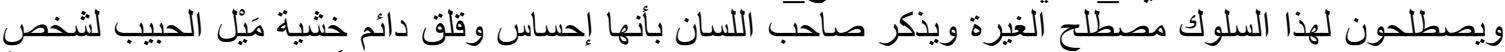

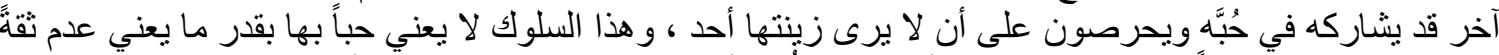

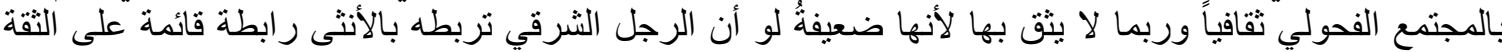

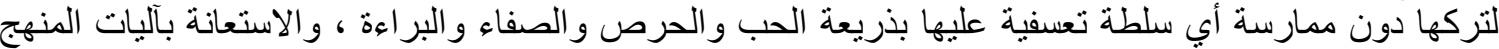

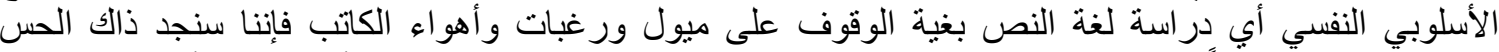

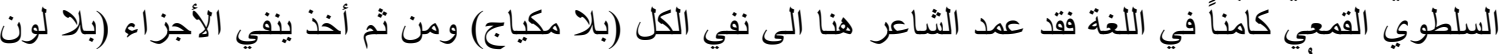

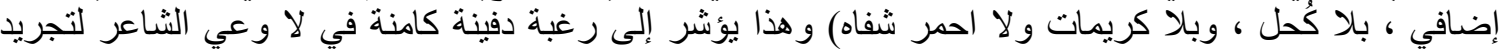

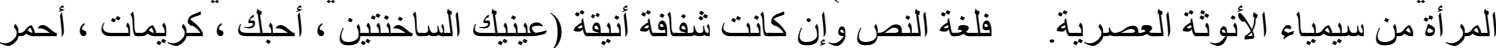

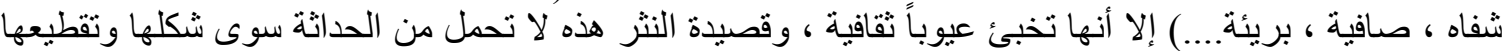

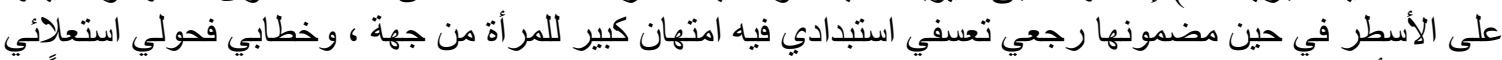

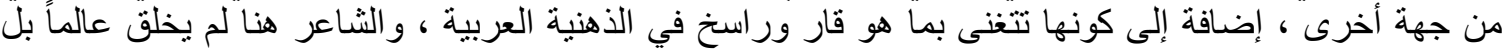

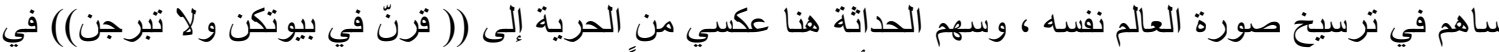

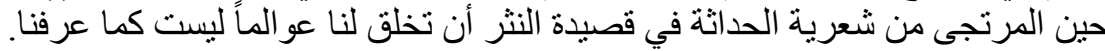

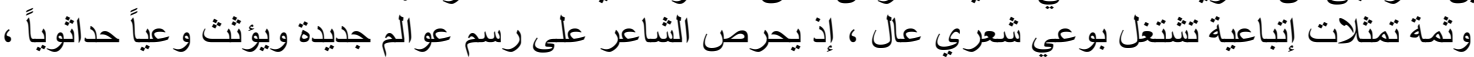

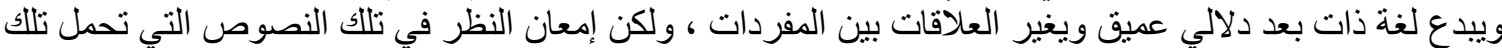

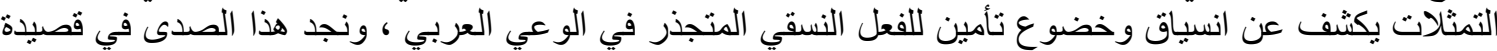

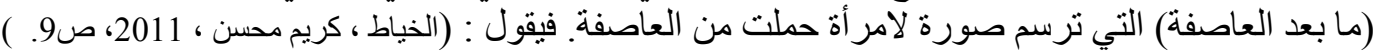

المر أة التي حملتُ من العاصفة

$$
\begin{aligned}
& \text { أغمضت عينيها } \\
& \text { وحلمت } \\
& \text { شعرت بقارب يتسلق شجرة } \\
& \text { تنكتب حلمها } \\
& \text { أعني فضيحتها } \\
& \text { المرّ أة التي حملت من العاصفة } \\
& \text { ماتتُ }
\end{aligned}
$$




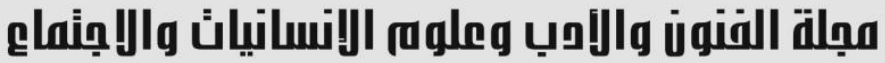

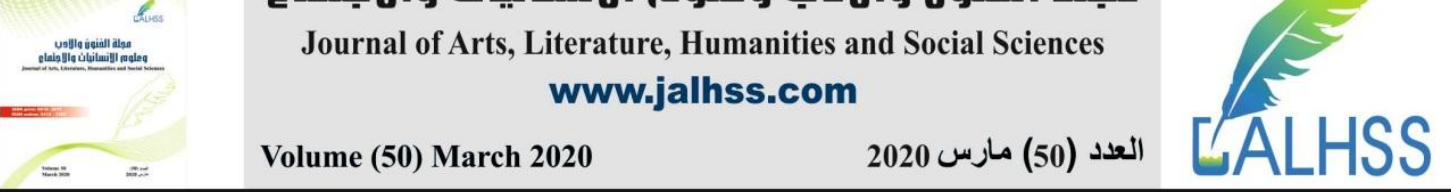

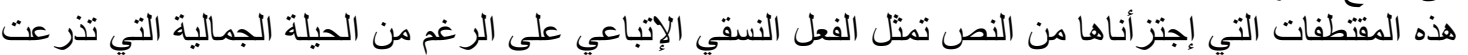

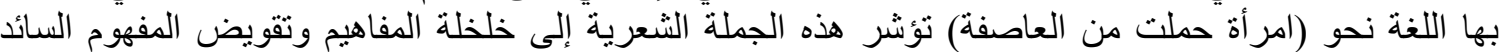

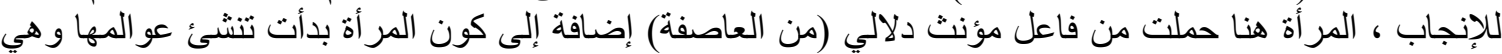

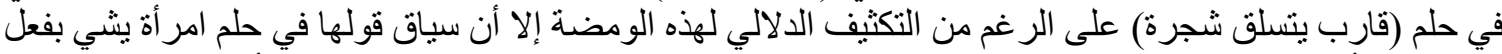

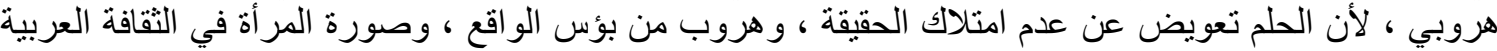

تكتنز بمضدون هروبي.

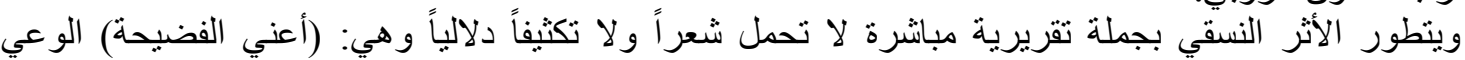

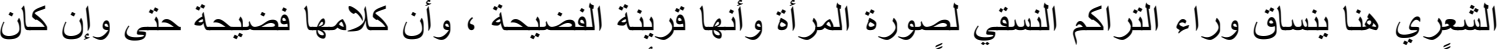

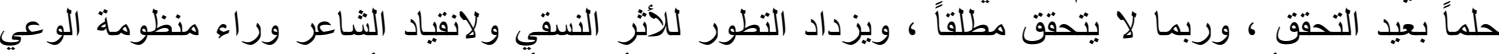

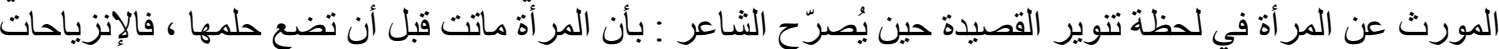

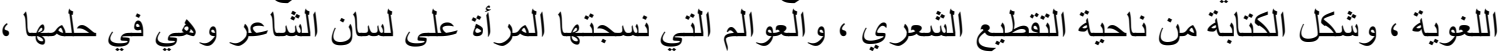

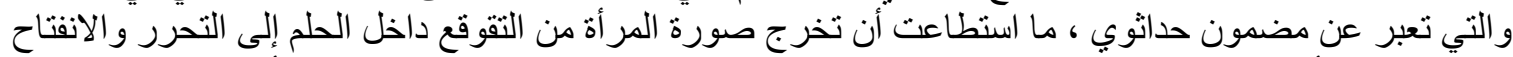

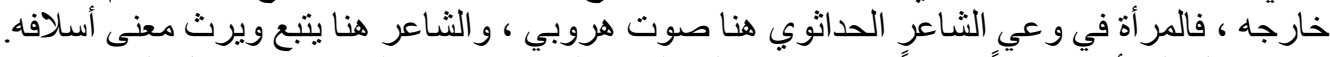

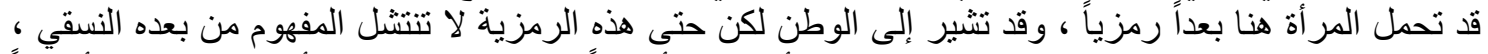

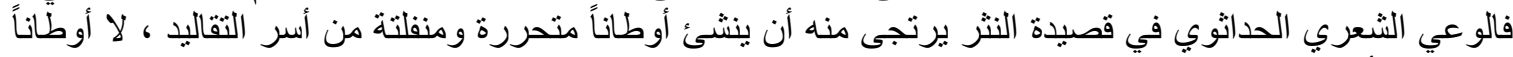
تموت قبل أن تضع التع حلمها.

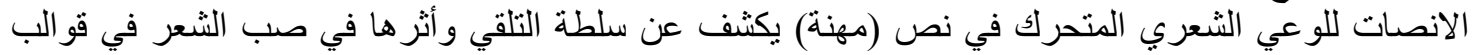

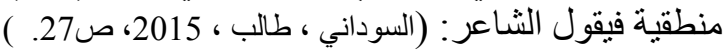

$$
\begin{aligned}
& \text { ابن البنّاء ....... بناءاء.......... ساعاتي } \\
& \text { ابن الحلّاق ... حلاق }
\end{aligned}
$$

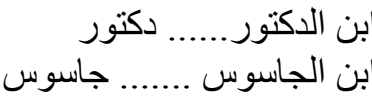

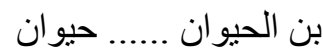

$$
\begin{aligned}
& \text { ابن المهندس ....... مهندس الئس .ئس } \\
& \text { ابن الخياط ...... خياط الفئ } \\
& \text { ابن القوّاد ............ قَّ اد } \\
& \text { فأبي جندي لذا ولدت قتيلاً }
\end{aligned}
$$

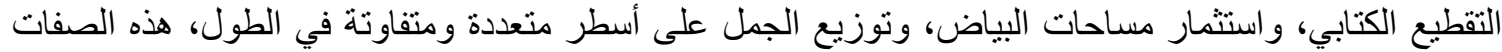

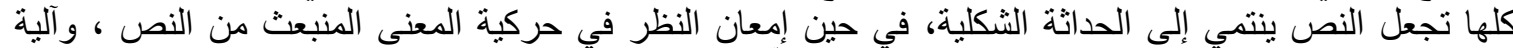

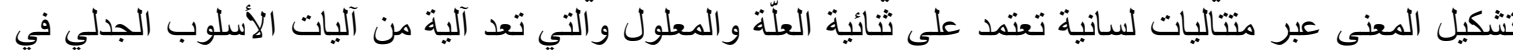

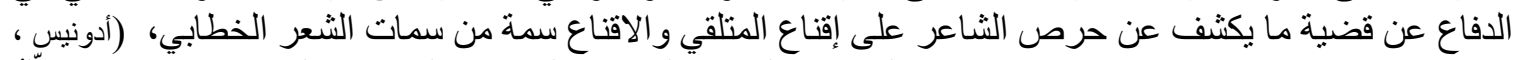

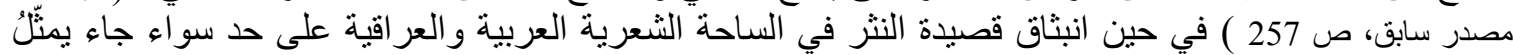

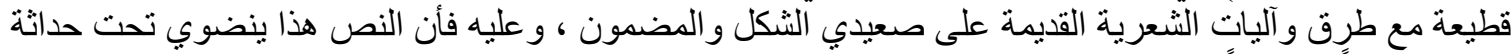

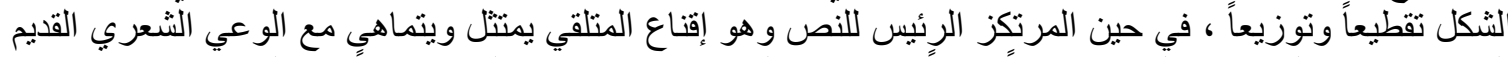

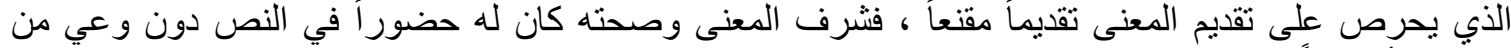

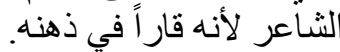




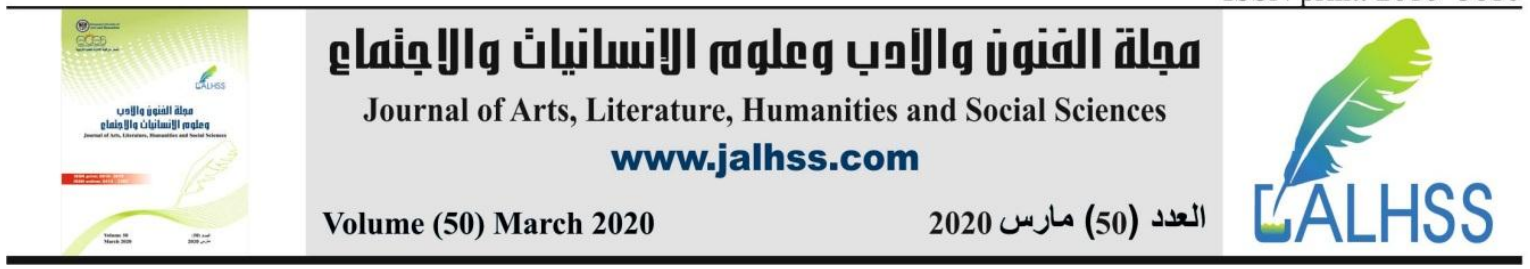

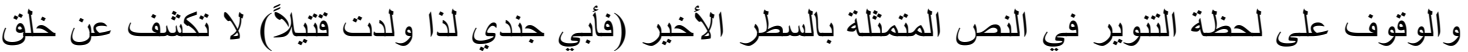

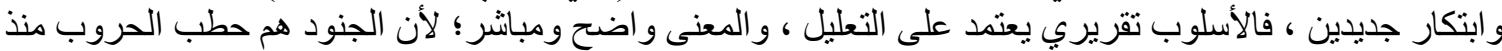

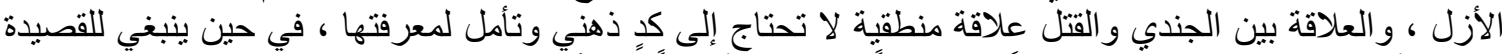

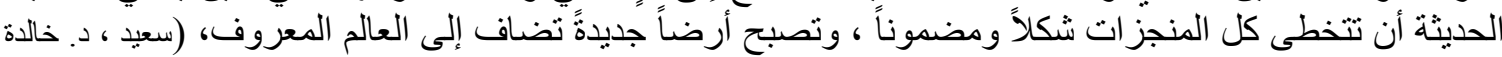

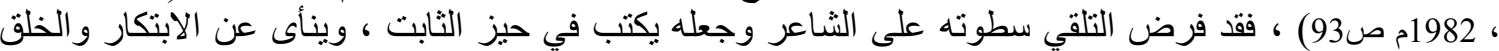

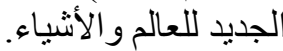

\section{نسق الفحولة (مفهوم الفحولة)}

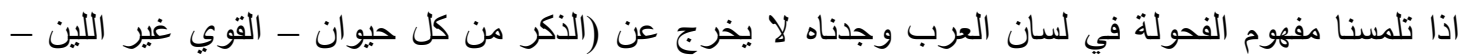

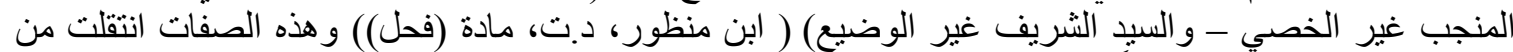

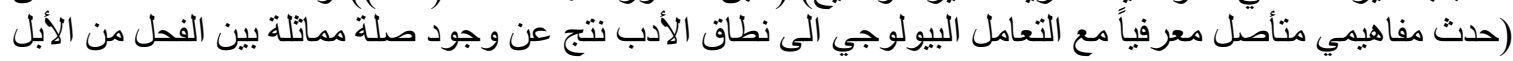

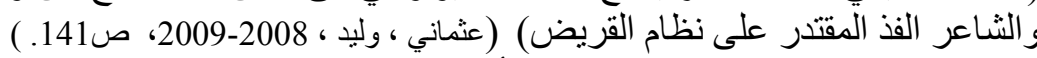

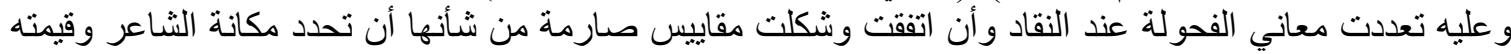

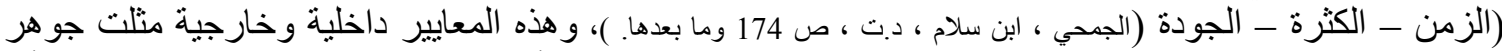

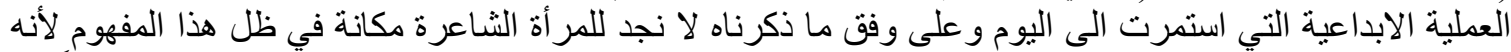

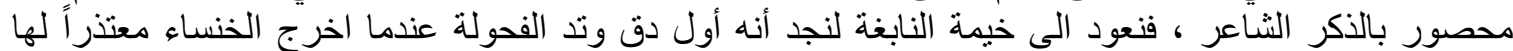

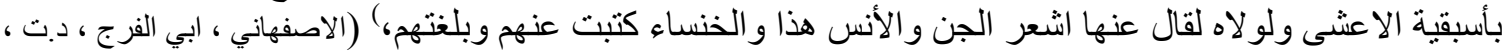

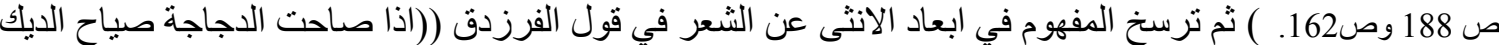

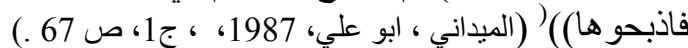

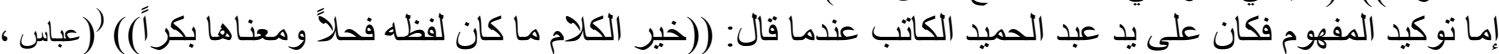

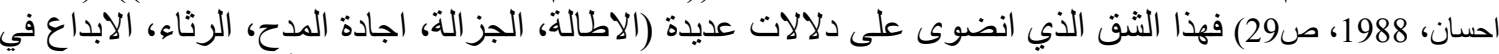

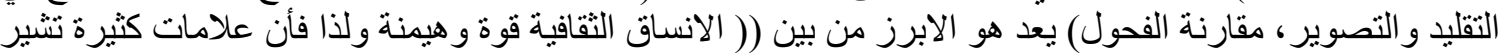

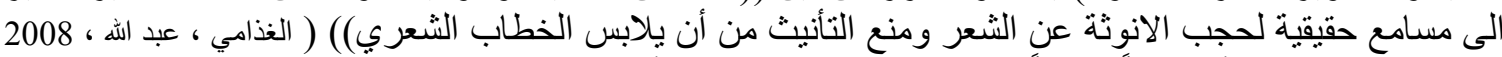

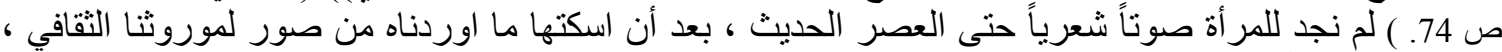

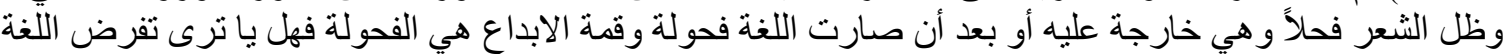

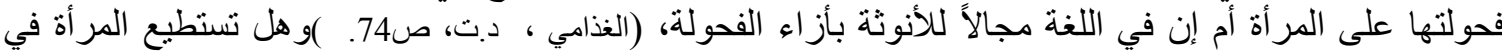

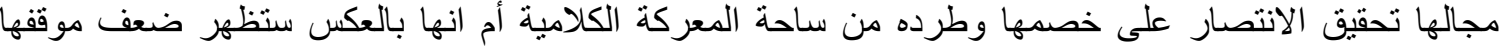

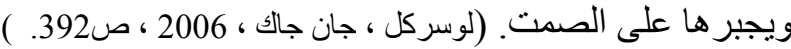

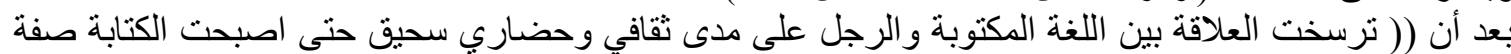

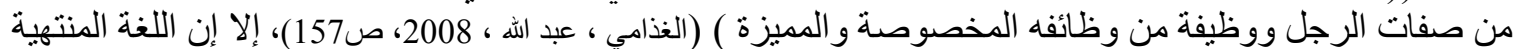

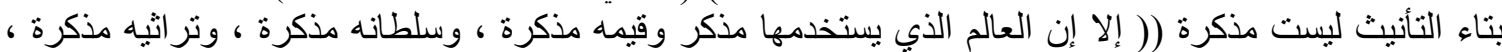

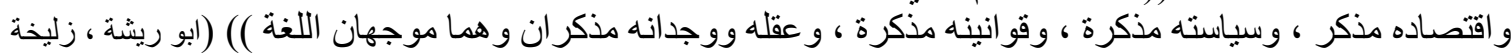

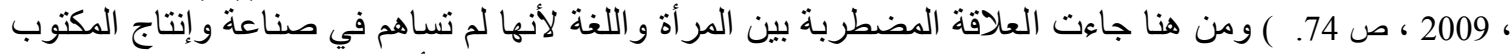

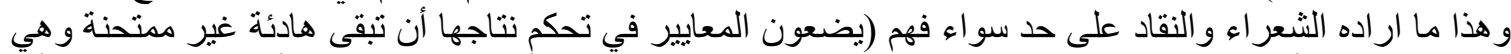

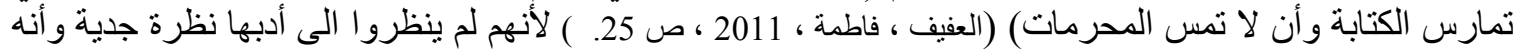

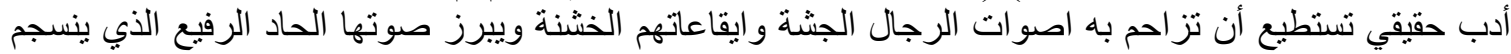

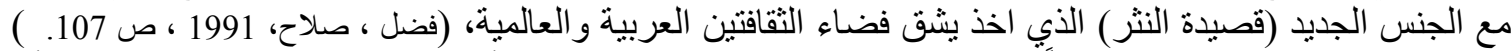

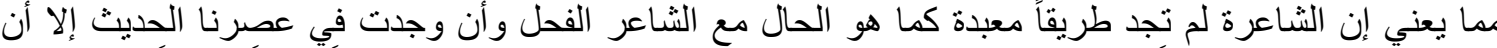

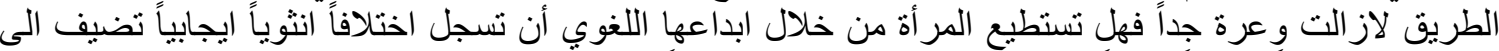

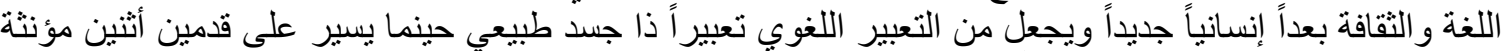

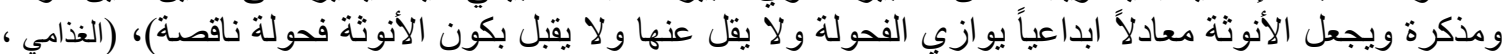




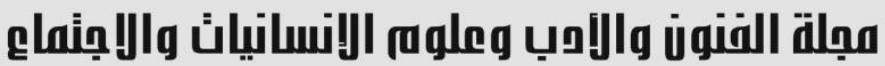

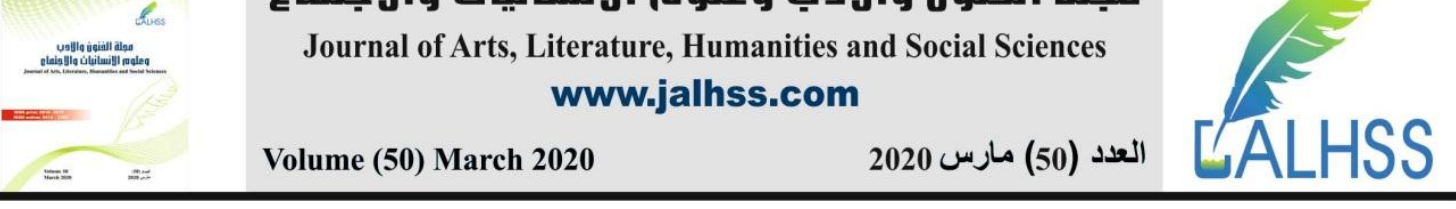

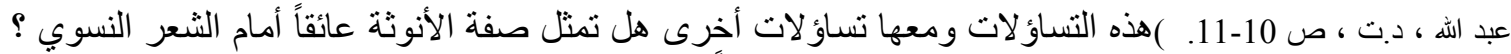

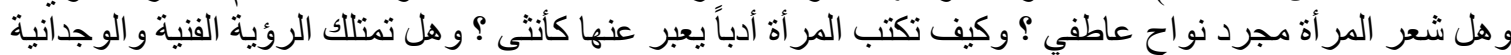

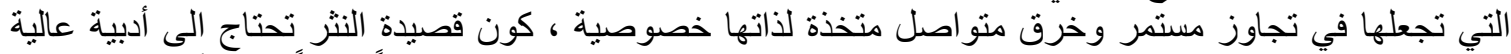

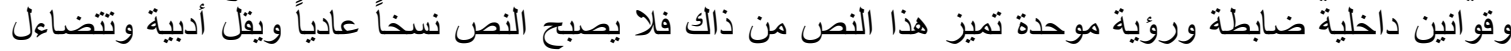

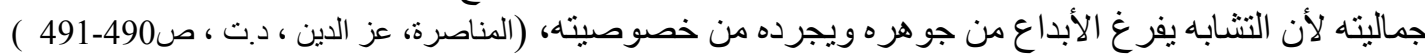

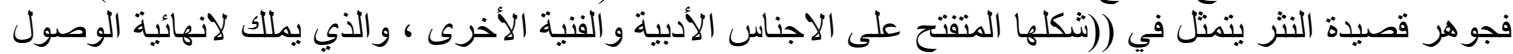

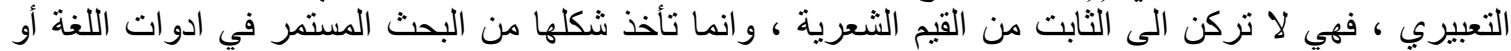

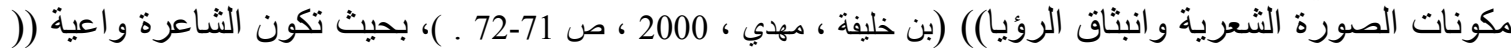

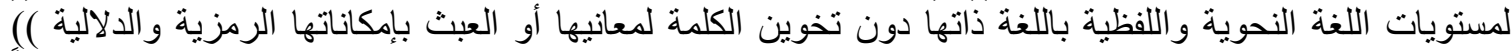

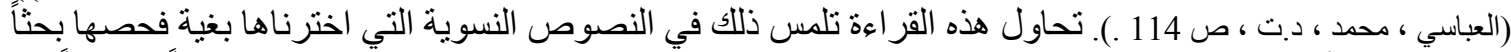

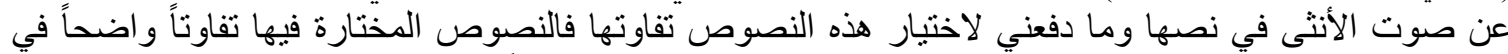

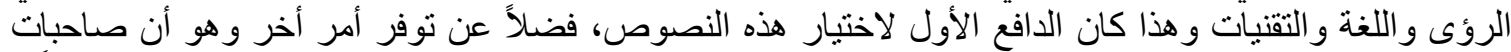

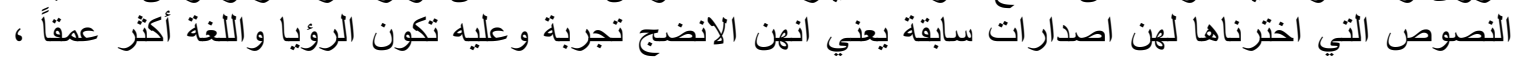

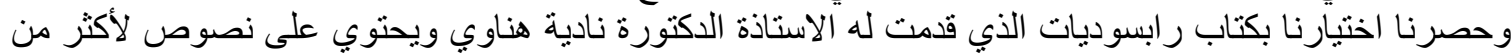

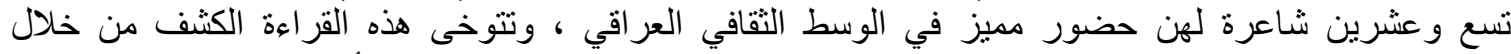

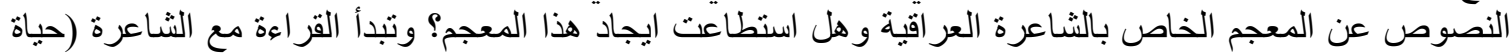

$$
\text { الثمري) التي عنونت نصها بسؤال (لماذا؟): }
$$

$$
\begin{aligned}
& \text { صار جرحي سيفي } \\
& \text { اجيد به تقطيع ذاتي } \\
& \text { وجسدي الصمت } \\
& \text { بسياط ذُكر اك يضرب } \\
& \text { كانوني انتظار } \\
& \text { ما أخلف و عدك انكي } \\
& \text { وانت أيها البعيد } \\
& \text { المقيم في دمي البهي } \\
& \text { بنصلك تقطع } \\
& \text { كبد حكاياتي } \\
& \text { واوردة خيالاتي } \\
& \text { وتحول فاكهني احجار الونا } \\
& \text { لماذا اوقدت القطيعة ؟ } \\
& \text { و عيوني للك دهور حنان؟ } \\
& \text { مالك؟ } \\
& \text { ما كنت حجر التو } \\
& \text { لتكسر نافذة قلبي } \\
& \text { أعد إلي ابتسامتي نافي } \\
& \text { التي فرت من ذاكرتي } \\
& \text { وقد الأرض لخطوي ذاكرني } \\
& \text { وتعال } \\
& \text { و لا تكن كمن في وهج } \\
& \text { الثمس يبحث عن في } \\
& \text { ضياء. }
\end{aligned}
$$


Journal of Arts, Literature, Humanities and Social Sciences www.jalhss.com

ويمكن بيسر ملاحظة عنوان القصيدة بعبر عن سطوة الدلالة و انفتاحها على معان ودلالات عديدة لأنه يصل الى كم

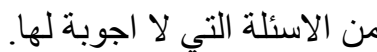

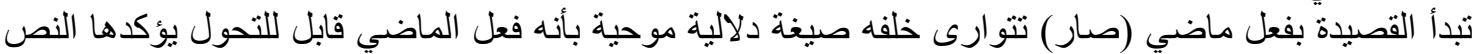

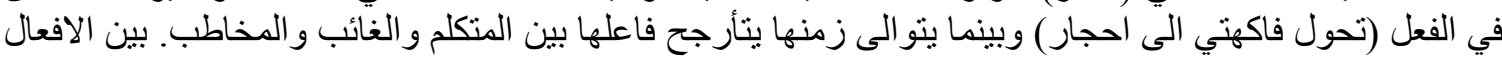

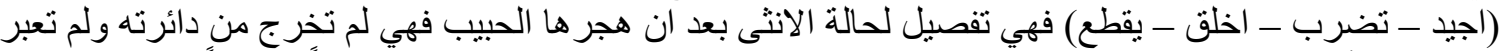

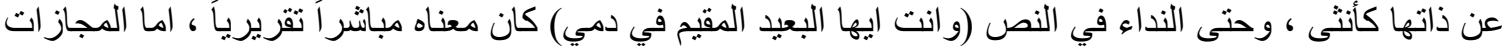

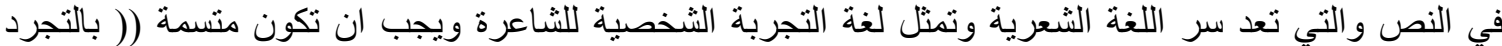

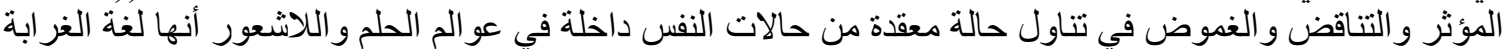

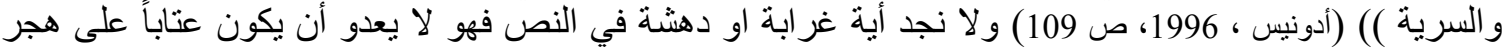

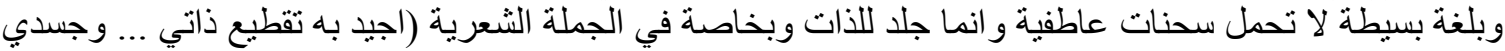

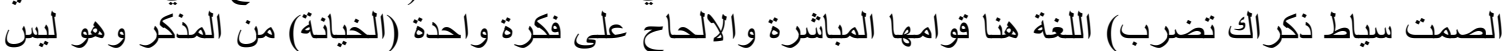

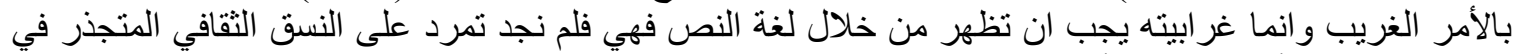

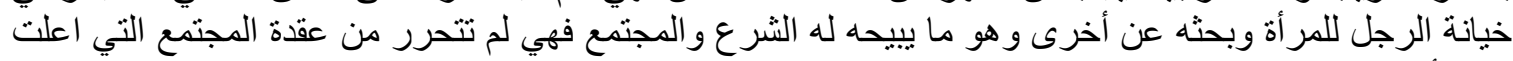

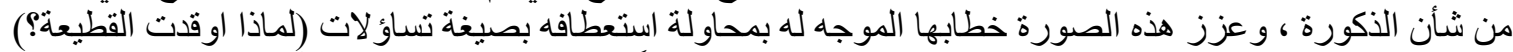

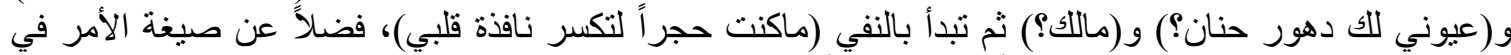

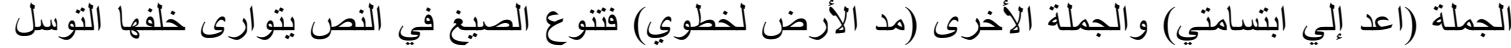

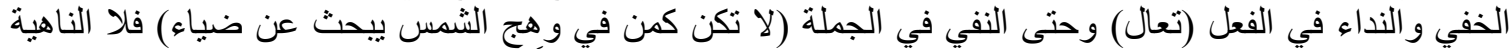

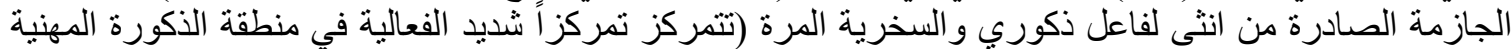

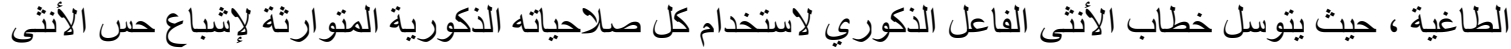

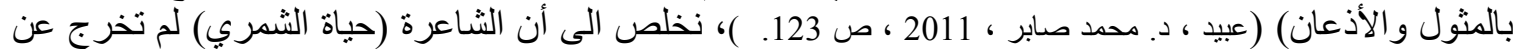

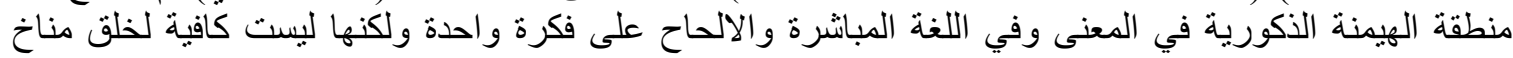

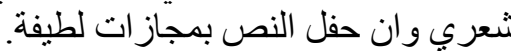

وفي نص الثاعرة (عايدة الربيعي):

$$
\begin{aligned}
& \text { طقوس وطنية }
\end{aligned}
$$

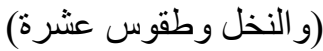

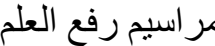

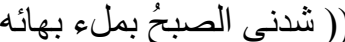

$$
\begin{aligned}
& \text { ونث ضيائه الوهاج فوق أهداب الطفولة سوسناً ور اح يثدو منشداً } \\
& \text { موطني ، موطني }
\end{aligned}
$$

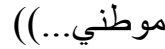

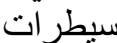

(منذ السلالات و انا اتطوع رحالة ، أنقب عن وطن ، فلا أجد سوى لافتة نقش عليها بدم الوطن:

قف للتفنش)

غفلة

(دوماً في احلامي أقف مقطعة الأوصال بين النساء ، عند بو ابة عادلة ،

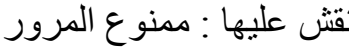

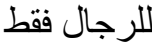

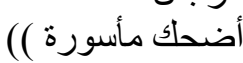

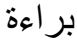

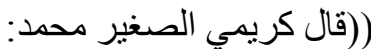

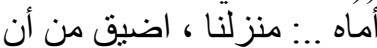




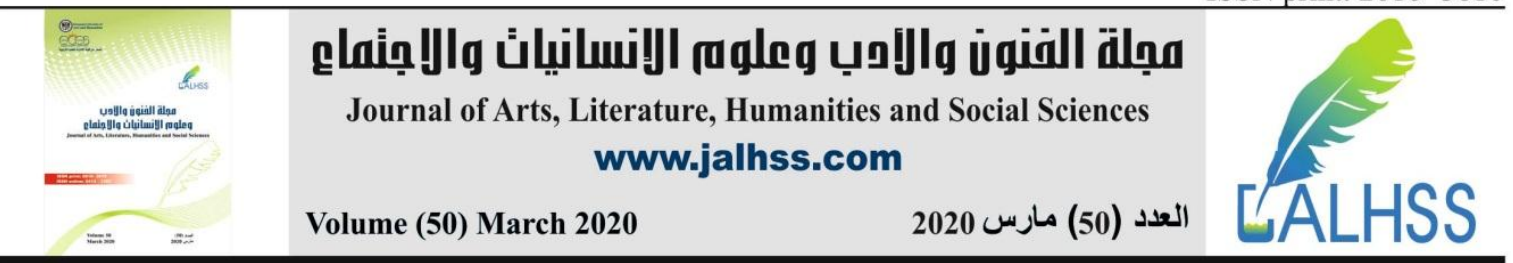

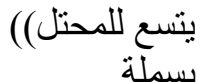

$$
\begin{aligned}
& \text { ((كلما أبصرت الحثالى ، يتجولون على أرضي ، اتلوا ((لإيلاف قريش إيلافهم)). }
\end{aligned}
$$

تحاول في نصها المعنون (طقوس وطنية) أن نثير الى معاني الخيبة بفقدان الوطن ومعاني العزة والكبرياء وتصور

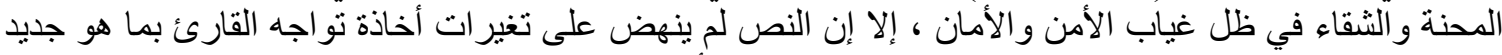

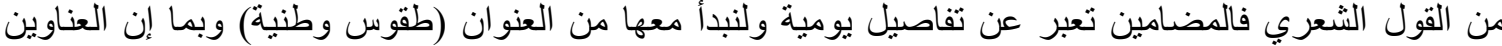

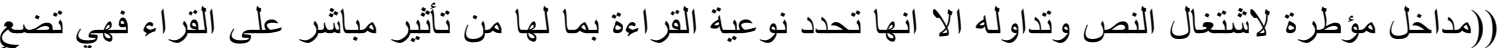

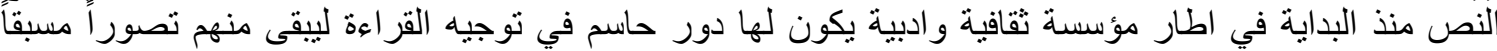

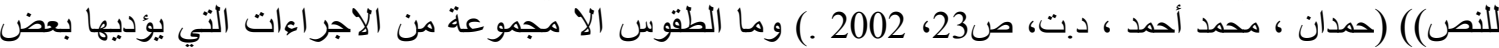

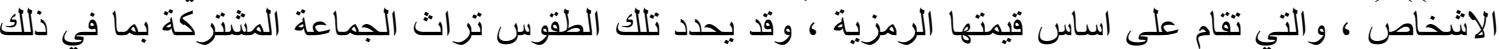

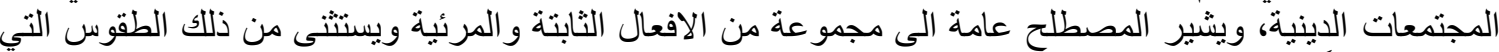

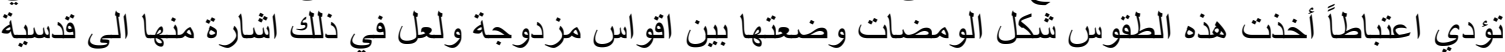

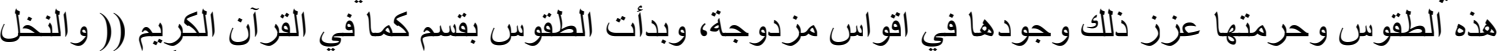

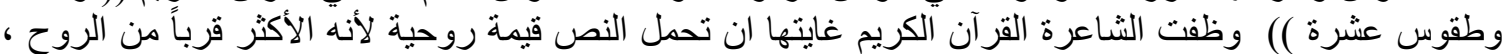

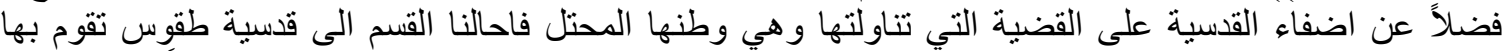

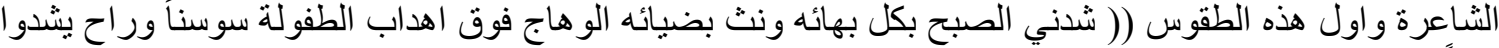

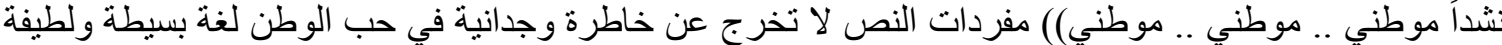

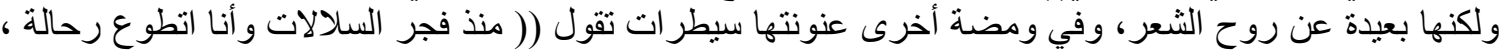

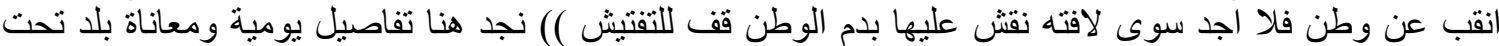

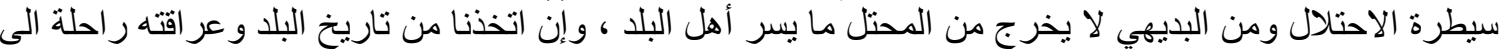

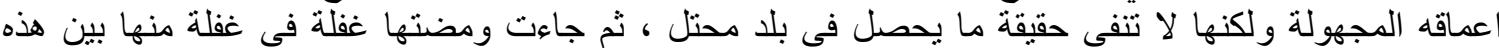

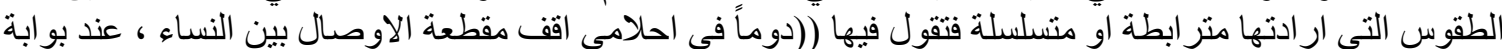

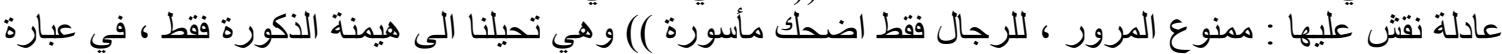

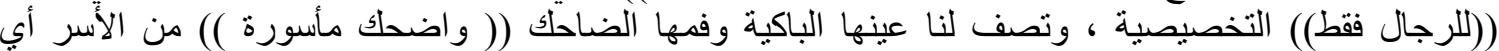

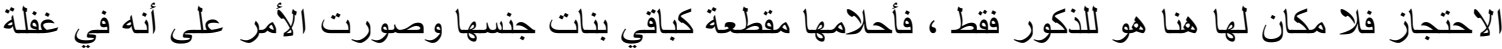

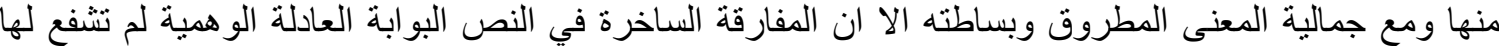

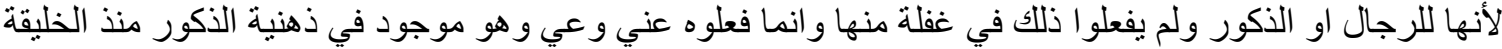

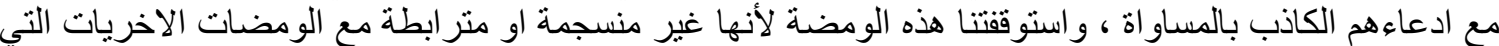

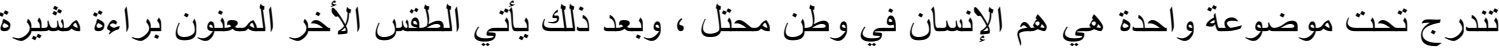

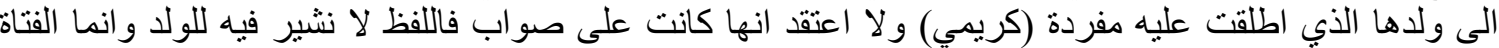

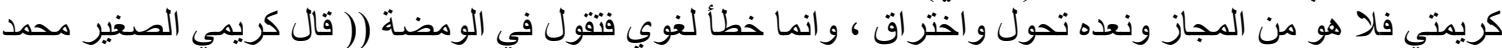

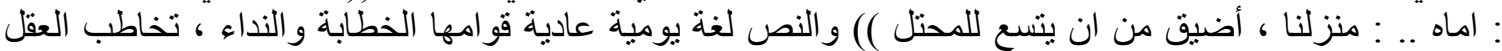

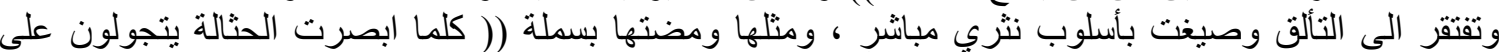

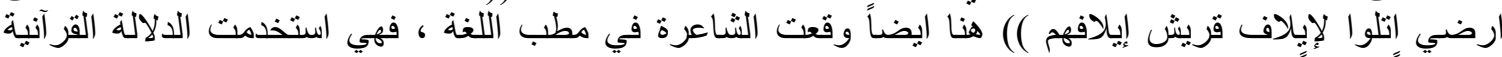

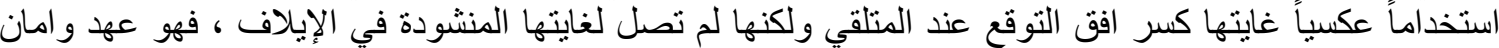

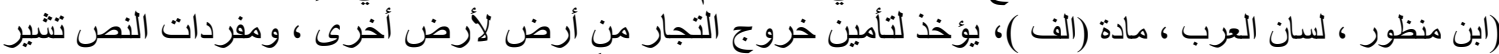

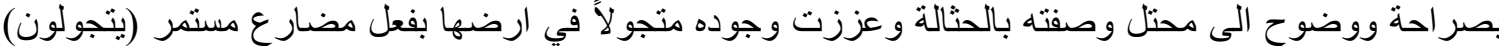

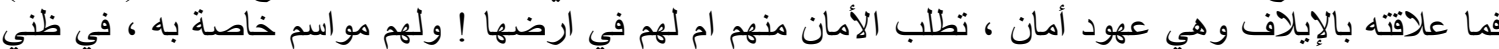

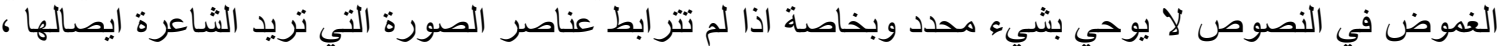

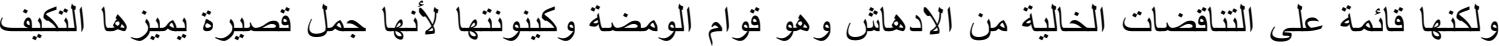

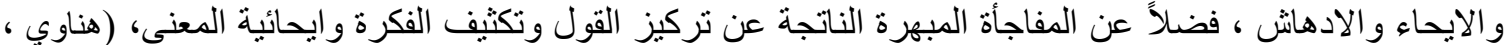

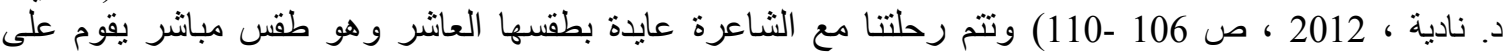




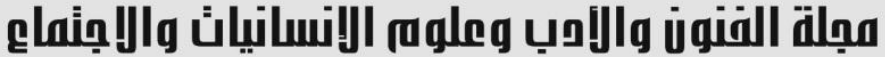

Journal of Arts, Literature, Humanities and Social Sciences

\section{www.jalhss.com}

الوضوح فتقول (( موطني ابك وجعي انها الخاتمات فالرؤى عراق و الحلم )) (( و النشيج موطني .. موطني فالجلال

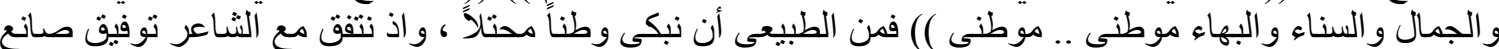
الذي يرى إن اختيار الكتابة في قصيدة النثر، (( اما ان يكتب شعر أ ممتازاً جداً أو رديئاً جداً وليس هناك الك خيار ثالث))

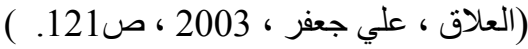

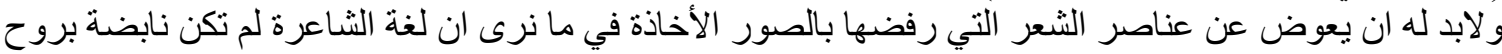

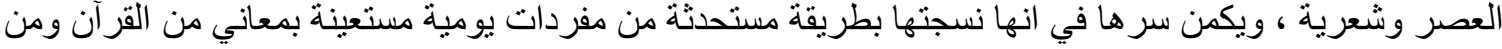

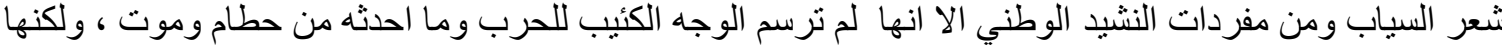

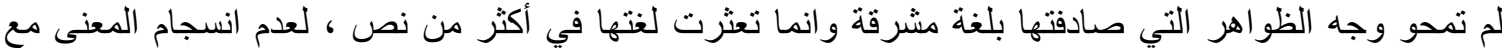

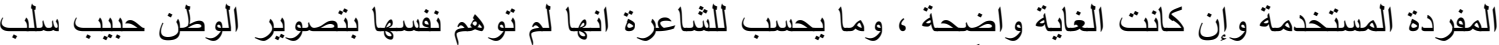
منهار غم عنها وتقع في فخخ الذكورة لغوياً ، إلا انها لم ترنق بلغتها الى ما يو ازي ما كتبوه تهن عن الوطن فبقيت بذلك اللغة

وفي قصيدة الثاعرة (آمنة محمود) (الدمعة الر اقصة) : روبة

كنت منشغلاً بمحو طيفها من مر آتلك

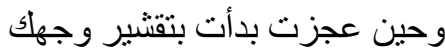
بينما كانت الملامح متداخلة

$* * * * *$

لأغنيتها على الهاتف رنين القداسة في مسمعك

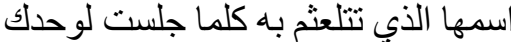
رأيتك تحاول قتلك بمسرى و ابتهالات . $* * * * *$

قطرة دمها على سبابتك تفيض مع كل قصيدة

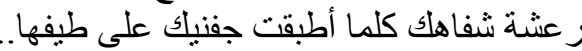
رأيتها. ور أيتك تدفن خاتمها البنفسج و هداياك التي لم تصلها في أماكن لا تدركها جاسوسات قلبك

تلف طيفها بعباءة شوقلك وتجهش

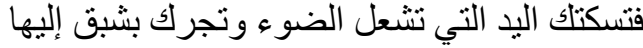
$* * * * *$ رائها في وجهك كان اسمها يخفو على شفاهك حين فاجأك السؤ ال:

(من تتمنى ان ترى الآن؟؟) بقسوة القاتل البريء كنت ترئ نطردها من أفكاري حتى رقصت دمعة ساخنة في عينيك الطيك

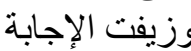
رأيتها .. هي الآن لا تشعر بالنصر

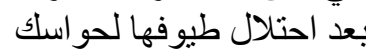

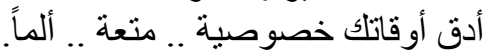
المقعد الأمامي لسيارتك ألك

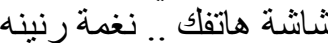
كل ذلك لا يعنيها بمقدار كونها الآن تبحث عنك فيك ..... و لا تجدك. 


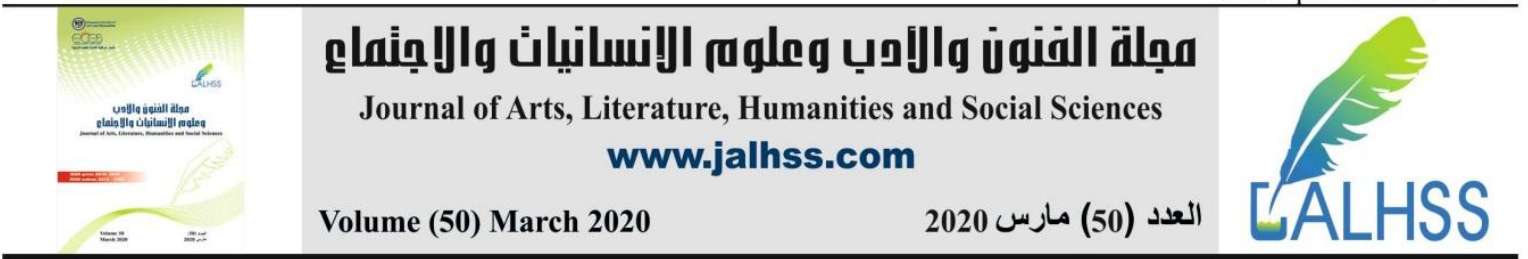

بكثف لنا العنوان عن طبيعة النص بوصفه مؤشر اً من مؤشر ات القر اءة نجد الثكوى و الحنين ، فالإنسان في تكوينه

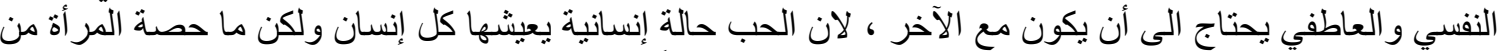

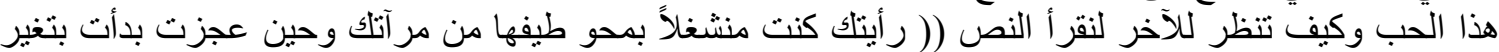

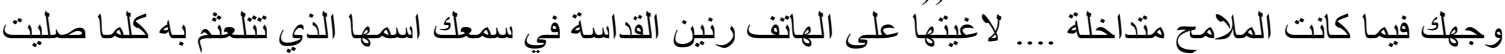

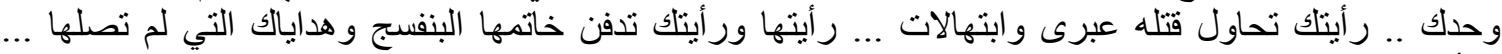

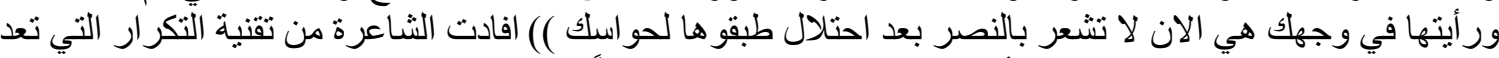

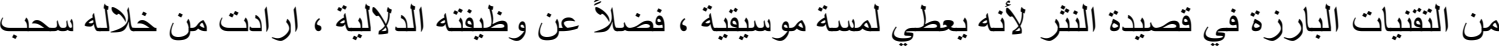

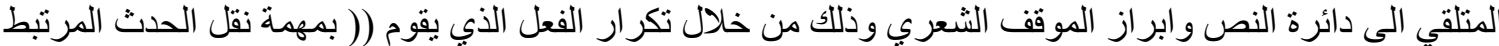

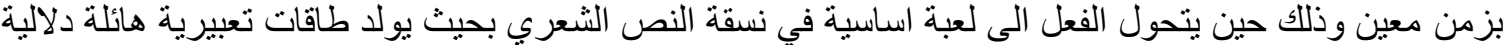

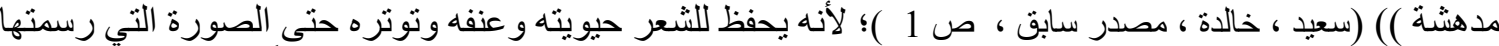

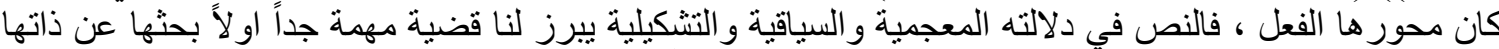

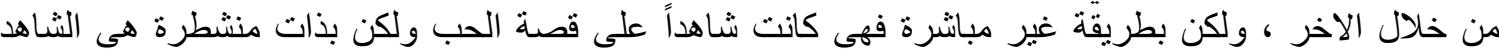

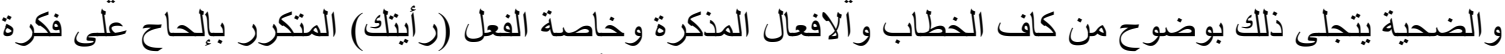

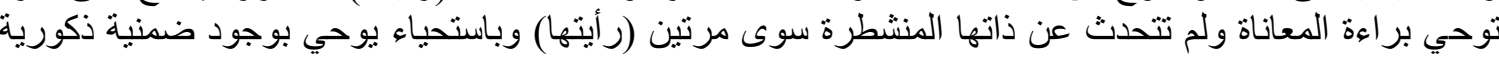

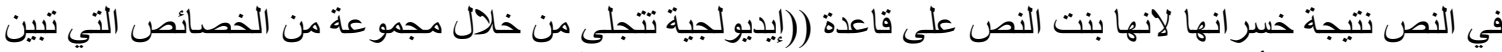

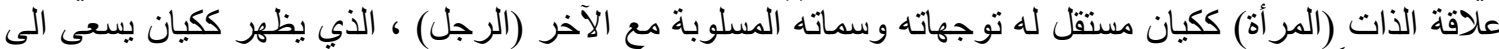

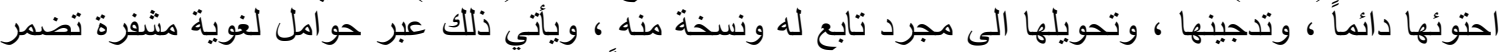

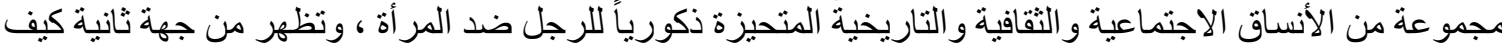

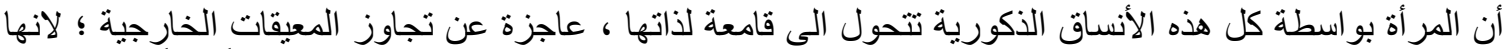

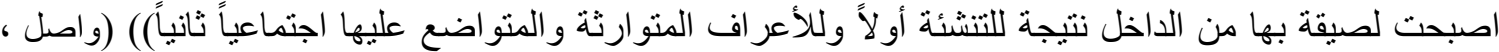

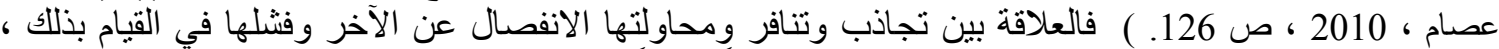

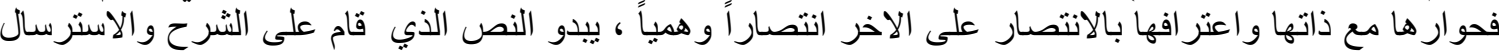

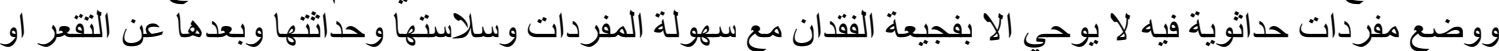

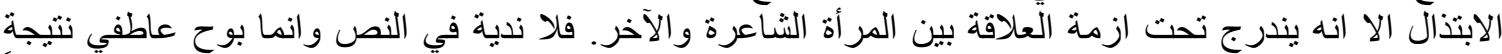

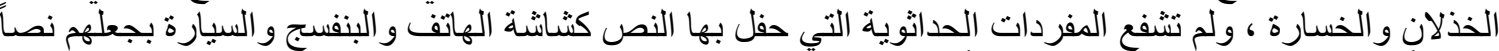
حداثوياً تجاوزت فيه الأنوثة الذكورة لغوياً. الخاتمة :

وبعد تمام هذه الدر اسة التي عرضت نسق الاتباع في قصيدة النتر ونسق الفحولة في القصيدة النسوية اتضحت لدينا

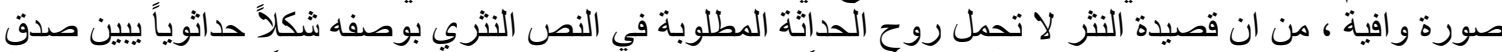

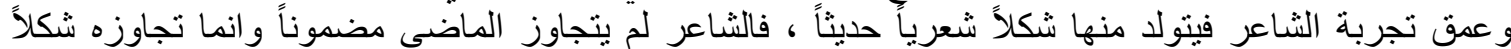

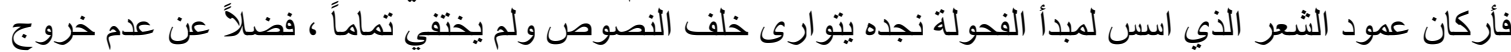
القصيدة النسوية عن البوح العاطفي وبلغة ذكورية. 


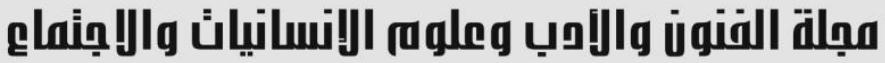

Journal of Arts, Literature, Humanities and Social Sciences www.jalhss.com

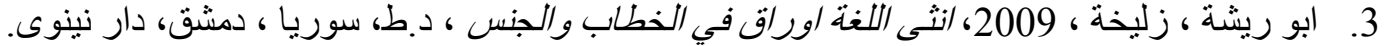

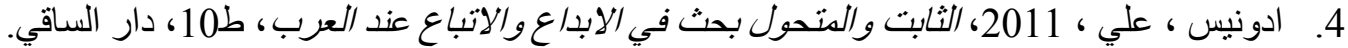
5.

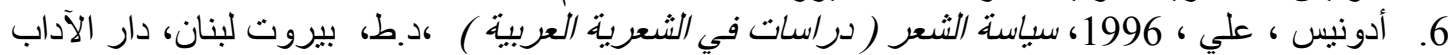

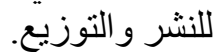

7. الاصفهاني ، ابو الفرج ، د.ت، الاغاني ، تح: د. احسان عباس ود. ابراهيم السعافين والاستاذ بكر عباس

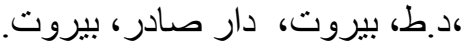
8. بن خليفة ، مهدي ، 2000 ، سلطة النص ، ط1، الجزائر ، منشورات الاختلاف، نشر رابطة كتاب

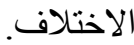

9. الجاحظ ، أبو عثمان عمرو بن بحر (ت 255ه) ، 1357هـ، الحيوان ، تحـ : عبد السلام محمد هارون ، ط.

10. الجمحي ، ابن سلام ، دت، طبقات فحول الثعراء ، تح: محمود محمد شاكر ، د.ط، مطبعة المدني ، مصر، المؤسسة السعودية.

11. حمدان ، محمد أحمد ، 2002، عتبات النص الادبي (بحث نظري) ، علامات في النص، المجلد(12)، العدد

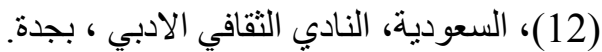

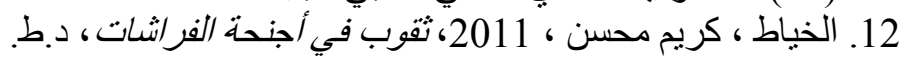

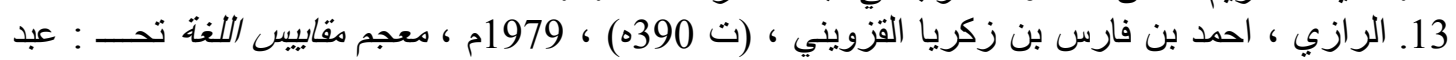

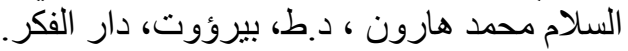

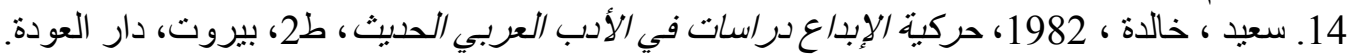

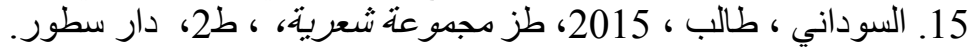
16. عباس ، احسان ، 1988، عبد الحميد بن يجيى الكاتب وما تبقى من رسائله، د.ط، عمان- الاردن، دار

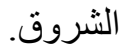

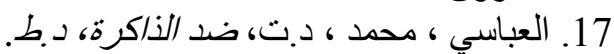

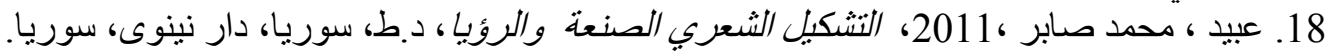

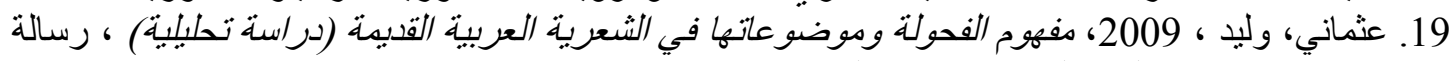

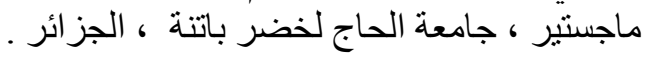
20. عريعر ، هيام عبد زيد عطية، 2012، الخطاب النقدي العربي الدعاصر وعلاقته بناهج النقد الغربي

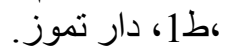

21. عطيه ، د. احمد عبد الحليم ، 2010، 2010، جاك دريدا والتفكبك ، ط1، بيروت، دار الفار ابي. 22. العفيف، فاطمة، 2011، لغنة الشعر النسوي العربي الدعاصر ، د.ط، الاردن، دار جدار للكير الكتاب العالمي

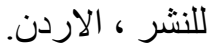

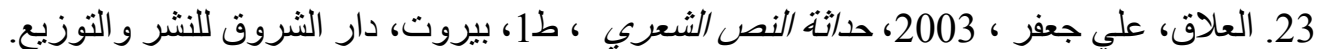

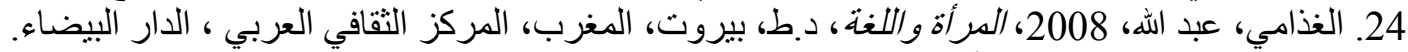
25. الغذامي ،عبد الله، 2008، تأنيث القصيدة والقارئ المختلف، ط4، بيروت، المغرب، المركز الثقافي الدار الثراه البيضاء.

26. فضل ، صلاح ، 1991، قراءة الصورة أو صور القراءة، ط1، دار الثروق، القاهرة ، ط1.

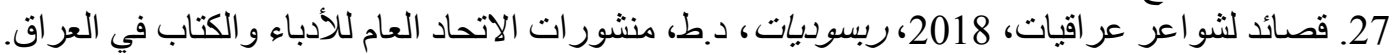

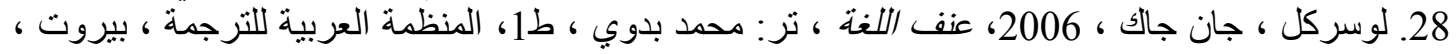




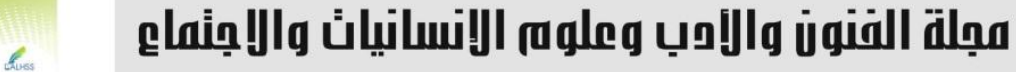

www.jalhss.com

29. الملائكة ، نازك ، د.ت، قضايا الشعر العربي ، ط5، بيروتـ لبنان، دار العلم للملايين.

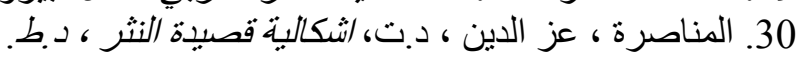

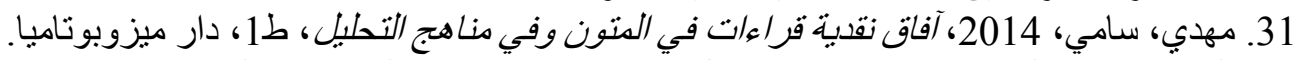

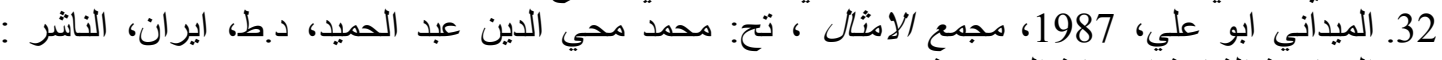

المعاونية الثقافية الاستانة الرضوية.

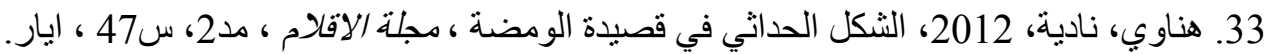

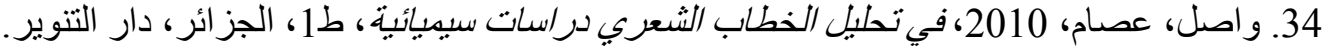
35. وجيه ، علي ، 2018، الصوائت والصوامت، د.ط، دار الرئ الر افدين. 


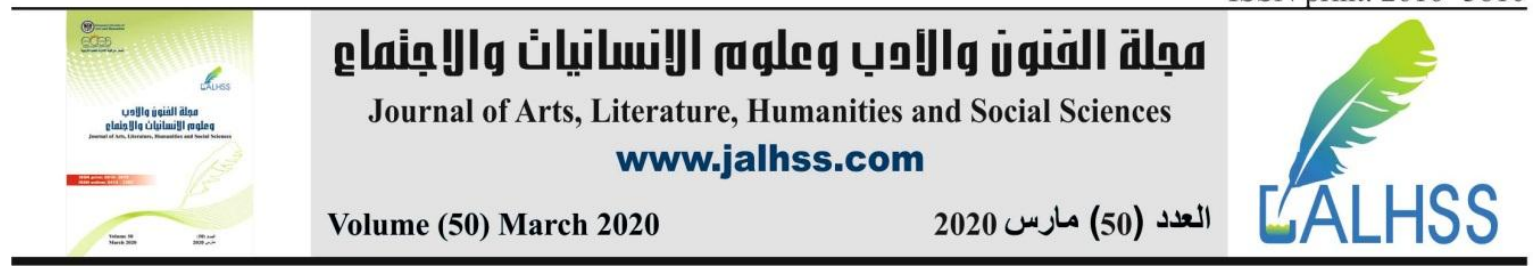

\section{References}

*The Holy Quran

1- Ibn Qutaybah, Poetry and Poets, (N.D). investigation: Ahmed Muhammad Shaker, Dar Al-Maarif, $2^{\text {nd }}$ Edition.

2- Ibn Manzoor, Muhammad bin Makram bin Ali, (d. 711 AH), Lisan Al-Arab, Dar Sader, Beirut.

3-Abu Risha, Zulekha, Female Language Papers in Discourse and Sex, Nineveh House, Syria, Damascus, 2009.

4- Adonis, the constant and the transformed research in creativity and followers of the Arabs, Dar al-Saqi, $10^{\text {th }}$ edition, 2011 AD.

5- Adonis, (2011). the constant and the transformed, a research into creativity and adherence among Arabs, the trauma of modernity and the power of poetic heritage, Dar Al-Saqi, $10^{\text {th }}$ edition.

6- Adonis, (1989). Arabic Poetry, dar aladab, Beirut, $2^{\text {nd }}$ edition.

7- Adonis, (1996). The Politics of Poetry (Studies in Arabic Poetry), Dar aladab for Publishing and Distribution, Beirut, Lebanon.

8- Al-Isfahani, Abi Al-Faraj, (N.D). Al-Aghani, investigation: Dr. Ihssan Abbas and Dr. Ibrahim Al-Sa'afin and Professor Bakr Abbas, Dar Sader, Beirut, Lebanon.

9- Bin Khalifa, Mahdi, (2000). The authority of the text, publications of alaikhtilaf, Algeria, published by the Association of the book of difference, Julia $1^{\text {st }}$ edition.

10- Al-Jahiz, Abu Othman Amr bin Bahr (255 AH), alhayawan, investigation: Abd alSalam Muhammad Harun, $2^{\text {nd }}$ edition, 1357 AH.

11- Al-Jumhi, Ibn Salam, (N.D). Layers of stallions of poets, investigation: Mahmoud Muhammad Shaker, Al-Madani Press, Saudi Foundation,Egypt.

12- Hamdan, Mohamed Ahmed, (2002). literary textual thresholds (theoretical research), signs in the text, Literary Cultural Club, Jeddah, Saudi Arabia, No. (12), part (46) vol. (12).

13- Al-Khayat, Karim Mohsen, (2011). holes in the wings of butterflies.

14- Al-Razi, Ahmad bin Faris bin Zakaria Al-Qazwini, (d. 390 AH), Dictionary of Language Standards, investigation: Abdul Salam Muhammad Harun, Dar Al-Fikr 1979 AD, Part 1, p. 362.

15- Saeed, Khaleda, (1982). The movement dynamics studies in modern Arabic literature, Dar Al-Awda, Beirut, $2^{\text {nd }}$ edition,

16- Al-Sudani, Talib, (2015). Tuz, Dar sutur, $2^{\text {nd }}$ edition.

17- Abbas, Ihsan, (1988). Abdul Hamid bin Yahya Al-Katib and the rest of his letters, Dar Al-Shorouk, Amman, Jordan.

18- Al-Abbasi, Muhammad, (N.D). Against Memory .

19- Obaid, Muhammad Saber, (N.D). The Poetic Formation of Work and Vision, Dar nynwa, Syria, 2011, p. 123.

20- Othmani, Walid, (2008-2009). The concept of virility and its topics in ancient Arabic poetry (analytical study), Master Thesis, Hajj Lakhdar Batna University, Algeria. 


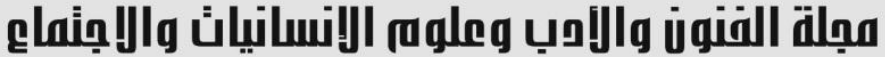

Journal of Arts, Literature, Humanities and Social Sciences www.jalhss.com

21- Ara'ir, Hayam Abd Zaid Atiya, (2012). Contemporary Arab Critical Discourse and Its Relationship to Western Curricula, Dar Tammuz, $1^{\text {st }}$ edition.

22- Attia, D. Ahmed Abdel Halim, (2010). Jack Derrida and Disassembly, Dar Al-Farabi Beirut, $1^{\text {st }}$ edition.

23- Al-Afif, Fatima, (2011). The Language of Contemporary Arab Feminist Poetry, Dar jidar for International Book Publishing, Jordan.

24- Al-Alaq, Ali Jaafar, (2003). Modernity of the Poetic Text, Dar Al-Shorouk for Publishing and Distribution, Beirut, $1^{\text {st }}$ edition.

25- Al-Ghadhami, Abdullah, (2008). Women and Language, The Arab Cultural Center, Casablanca, Morocco, Beirut, Lebanon.

26- Al-Ghadhami, Abdullah, (2008), The feminization of the poem and the different reader, Cultural Center of Casablanca, Morocco, Beirut, Lebanon, $4^{\text {th }}$ edition.

27- Fadl, Salah, (1991). Reading a Photo or Reading Pictures, Dar Al-Shorouk, Cairo, I 1.

28- Poems by Iraqi poets, (2018), Rhapsody, Publications of the General Union of Writers and Writers in Iraq.

29- Lucercle, Jan-Jack, (2006). Language Violence, Translation: Muhammad adawi, Arab Organization for Translation, Beirut, Lebanon, $1^{\text {st }}$ edition,.

30- Al-Malaikah, Nazik, (N.D). Arab Poetry Issues, Dar Al-Alam for Millions, Beirut, Lebanon, $5^{\text {th }}$ edition.

31- Almunasara, Izz al-Din, the problematic of the prose poem, and the aforementioned opinion of Dr. Muhammad Al-Badri in his response to almunasara questions about the prose poem.

32- Mahdi, Sami, (2014), criticism Prospects, Readings in Metn and in Methods of Analysis, Dar Mesopotamia, $1^{\text {st }}$ edition.

33- Al-Maydani, Majmae Al-Amthal, (1987), Investigation: Muhammad Mohi al-ddin Abdul-Hamid, Publisher: Cultural Cooperative, Al-Astana Al- Radwa, Iran.

34- Hanawi, Nadia, (2012), the modern form in the flashing poem, Al-Aqlam Magazine, D-2, S47.

35- Wasal, Essam, (2010), In the analysis of poetic discourse, Sinaiological. studies, Dar Al Tanweer, Algeria, $1^{\text {st }}$ edition.

36- Wajih, Ali, (2018), Voices and Silos, Dar Al-Rafidayn. 